Revue d'histoire de l'Amérique française

RAS REVUE D.HISTOIRE DE L'AMÉRIQUE FRANÇAISE

\title{
Index analytique des articles et des notes de recherche
}

Index, 1987

Index des volumes XXXI-XL (juin 1977 - printemps 1987)

URI : https://id.erudit.org/iderudit/305682ar

DOI : https://doi.org/10.7202/305682ar

Aller au sommaire du numéro

Éditeur(s)

Institut d'histoire de l'Amérique française

ISSN

0035-2357 (imprimé)

1492-1383 (numérique)

Découvrir la revue

Citer ce document

(1987). Index analytique des articles et des notes de recherche. Revue d'histoire de l'Amérique française, 9-47. https://doi.org/10.7202/305682ar d'utilisation que vous pouvez consulter en ligne.

https://apropos.erudit.org/fr/usagers/politique-dutilisation/ 


\section{Index analytique des articles et des notes de recherche}


Agniers (tribu amérindienne), motivations à la bataille du Long-Sault, Nouvelle-France, 35, 2: 167 ss

Abandon d'enfants, Montréal, 40, 4: 537-559

Abjuration des protestants, Nouvelle-France, 31, 3: 338-342

Aboiteaux, technique acadienne, NouvelleFrance, 37, 3: 403-405

Acadie, Nouvelle-France, 37, 3: 399-416

Acadiens, Louisiane, collection d'essais, 34, 1: $95-98$

Accouchement, discours médical, 38, 1: 29

Acte d'affrètement de navire, étude des marchands, 38, 2: 215, 216

Acte de procuration, étude des marchands, 38, 2: $210-212$

Acte de transport, étude des marchands, 38, 2: 217,218

Acte de vente de terres et d'immeubles, étude des marchands, 38, 2: 213, 214

Acte des Tenures du Canada (1825), mode de propriété des terres, 36, 2: 169 ss

Acte général des mines de Québec de 1880, 37, 4: 592-597

Actes notariés, étude des marchands, 38, 2: 203-222

Actes pontificaux, collection publiée par l'École sociale populaire, 35, 4: 572

Action corporative (organisme), oeuvre de l'École sociale populaire, 35, 4: 580-583

Action libérale nationale, participation des Jeune-Canada, 40, 1: 13, 14; René Chaloult, 39, 1: 27 ss

Administrateurs, entreprises, Mauricie, 38, 2: 181-201

Administration financière, Nouvelle-France, 32, 2: 181-202

Administration municipale, réforme, Montréal, 37, 2: 192, 193

Admission aux études en médecine, normalisation, 37, 1: 54-57

Adultes, éducation des, écoles du soir, 34, 4: 597-625

Affaires publiques, émissions à la télévision de Radio-Canada, 36, 2: 213-239

Affiliation syndicale, Confédération des travailleurs catholiques du Canada, 34, 3: 396 399

Agences scientifiques et techniques fédérales, histoire des, indications bibliographiques, 35, 2: $201 \mathrm{ss}$

Agriculture, Acadie, Nouvelle-France, 37, 3: 403-405; Gaspésie, 36, 4: 492 ss; hiérarchie de la paysannerie, seigneurie de Saint-Hyacinthe, 40, 3: 373-407; historiographie, 33, 1: 67-78; Mauricie et Québec (province), 35, 4: 537-562; Nouvelle-France, 37, 3: 424-426; Québec (province), 39, 2: 257$259 ; 40,2: 275,276,280$; régions défavorisées, France-Québec, 35, 2: 253-261; Saguenay-Lac Saint-Jean, 31, 1: 16, 17; stratégie foncière des habitants, Québec (région), 39, 4: 551-581; thèse de Maurice Séguin, 38, 4: 573-578; transition du féodalisme au capitalisme, $35,1: 81 \mathrm{ss}$; travail des enfants, Québec (province), 38, 1: 52 ss; vallée du Richelieu, 39, 3: 407-413; voir aussi Système agro-forestier

AINEY, Joseph (président du Congrès des métlers fédérés et du travail), politique municipale, Montréal, 37, 2: 189 ss

AKERMAN, John (économiste), théorie économique, 33, 3: 421-424

Alcan, Mauricie, 37, 1: 11 ss; travailleurs, Saguenay, 37, 2: 291-308

ALDRED, Julian Edward (directeur de la Shawinigan Water and Power), 38, 2: 190, 191

Algonquiens (tribu amérindienne), croyances du Kokotché, 35, 3: 377-381

Aliénation mentale, voir Asile psychiatrique

Aliénation à titre onéreux, transmission des terres, Calixa-Lavallée (village), 34, 3: 334, 335

Alimentation, marchands-négociants, Québec (ville), 36, 4: 530-532; population, Montréal, 36, 4: 521, 522

Allaitement, discours médical, 38, 1: 29

Allemagne, histoire de la famille, 39, 2: 168, 179,180

Allemands, établissement en Louisiane française, 33, 1: 51-65

Allocations familiales, programme d', Canada, 40, 1: 73-95

Alphabétisation, Nouvelle-France, 31, 1: 6567; patrimoine foncier, Québec (région), 39, 4: 573; Québec (ville), 39, 1: 63-76

ALTHUSSER, Louis (philosophe), rapport famille/Église/État, 34, 2: 200

Aluminium, Alcan, Saguenay, 37, 2: 291-308; Mauricie, 37, 1: 11 ss 
Aluminium Company of America, voir Alcan ALVORD, Clarence (historien), colonisation de l'Illinois, 39, 4: 583-591

Aménagement du territoire, Gaspésie, 36, 4: 483-506

Aménagement rural, régions défavorisées, France-Québec, 35, 2: 253-261

Amérindiens, allocations familiales, Canada, 40, 1: 88; image chez les Européens, 39, 2: 263-270; relations avec les Français, Nouvelle-France, 35, 2: 169 ss

Amiante, grève de l', ouvrage de Pierre-Elliott Trudeau, 37, 2: 203

Amiante, industrie de l', Cantons de l'Est, 33, 2: 187-195; Québec (province), 37, 4: 574 ss

Analphabétisme, voir Alphabétisation

Ancien Régime (France), démographie différentielle, 38, 3: 357-359

ANDERSON, Michael (démographe), histoire de la famille, Europe, 39, 2: 171, 172, 179

Angleterre, droit de la faillite, 40, 2: 218, 219; histoire de la famille, $39,2: 165 \mathrm{ss}$; libéralisme, 40, 4: 510-512; révolution agricole, 39 , 3: 377,378 ; révolution démographique, 39, 3: 377,378 ; révolution industrielle, 39 , 3: 379-386; révolution politique, $39,3: 385$; stratégie d'attaque de la Nouvelle-France, 37, 1: 23-26; transition au capitalisme, 39, 3: $374-388$

ANGUS, lan (historien), Parti communiste canadien, 37, 2: 314

Annales, École des, influence au Québec, 33, 3: 357-386; 38, 2: 229, 230; problématique pour l'histoire canadienne, 33, 3: 394-402

ANNAOTAHA, Étienne (chef des Hurons), bataille du Long-Sault, Nouvelle-France, $35,2: 167$ ss

Anthropologie, histoire de la famille, Europe, 39. 2: $168 \mathrm{ss}$

Anticléricalisme, France, venue au Québec des congrégations religieuses, $36,3: 389-411$

Anticommunisme, École sociale populaire, 32, 2: 225-228; grève du textile, Lachute, 37,2 : 280-282

Antilles françaises, Jean-Baptiste Colbert, 37, 3: $439 \mathrm{ss}$

Antilles/France/Nouvelle-France, commerce de la morue, 37, 4: 558, 559

Anti-militarisme, violence, Québec (province), $37,1: 71-74,77$

Appel de la race, L' (roman de Lionel Groulx), opposition de l'abbé Camille Roy, 32, 3: 401-405
Apprentissage, tannerie-cordonnerie, Québec (ville), Nouvelle-France, 34, 3: 344 ss Approvisionnement de la Nouvelle-France, Guerre de la Conquête, 36, 3: 413-426

Approvisionnement en blé, régime seigneurial, Montréal, 36, 2: 241-262

ARCHAMBAULT, Joseph-Papin (jésuite), directeur de l'École sociale populaire, 35, 4: 563-587; promoteur de l'École sociale populaire, 32, 2: $206 \mathrm{ss}$

Architecture militaire, fort de Chambly, Nouvelle-France, 37, 1: 27-34

Archives canadiennes, conservation et publication par la Literary and Historical Society of Quebec, 35, 2: $187 \mathrm{ss}$

Archives religieuses, Sacrée Congrégation de la Propagande en Amérique du Nord, 33, 2: 197-214

ARENSBOURG, Charles Frédérick d', chef de la colonie allemande en Louisiane française, $33,1: 58$ ss

Argenterie, artisans, Québec (ville) et Montréal, Nouvelle-France, 40, 3: 363-365

ARIĖS, Philippe (historien), famille moderne, 39, 2: 206, 207; histoire de la famille, Europe, 39, 2: 165-167

Aristocratie foncière, transition au capitalisme, Angleterre, 39, 3: 383-386

Armateurs de navires de pêche, Terre-Neuve/ Marseille, 40, 2: 195-214

Armée, aide au pouvoir civil, Québec (province), 37, 1: 67-79; bilinguisme, 37, 1: 72, 74

ARMOUR, Robert jr. (rédacteur du Sherbrooke Gazette and Townships Advertiser), 31, 2: 250

Artillerie, Nouvelle-France, 37, 1: 37-42

Artisans, chaussure, Montréal, 31, 2: 187-210

Artisans du cuir, Québec (ville), NouvelleFrance, 34, 3: 341-356

Arvida, travailleurs de l'Alcan, 37, 2: 291-308

Asile psychiatrique, Québec (province), 39, 3: 345-367

Asile, salles d', Soeurs Grises de Montréal, 34, 1: $27-55$

Assimilation, Franco-Américains, 34, 4: $563 \mathrm{ss}$

Association des manufacturiers de chaussures de Montréal, entente avec la Fédération canadienne des cordonniers, 36,1 : 81 ss

Association des médecins de langue française de l'Amérique du Nord, fondation, 35, 3: 361 
Association médicale du Canada, normalisation des études de médecine, 37, 1:55, 59, 61; réforme de la médecine, 35, 3: 358, 359

Association ouvrière catholique de Hull, 32 , 4: $604-610$

Association syndicale féminine catholique de Hull, 32, 4: 608-613

Associations, élites, Saguenay-Lac Saint-Jean, 39, 1: 16-21

Assomption, L' (village), marchands ruraux, 39, 3: 323-343

Aurore, L' (navire français), cargaison pour la Nouvelle-France, 36, 3: 417 ss

Auto-consommation, économie paysanne, 40, 3: $381-383$

Autonomie des femmes et avortemient, discours féministe, Québec (province), 37, 1 : 88,89

AVAKUMOVIC, Ivan (historien), Parti communiste canadien, 37, 2: 311

Avortement, discours féministe, $37,1: 87$; discours médical, 38, 1: 27, 28; droit à $l^{\prime}$, Québec (province), 37, 1: 81-90

Ayers, compagnie, grève du textile à Lachute, 37, 2: $271-289$

BABCOCK, Robert (historien), syndicalisme au Canada, 37, 2: 179

BAGG, Stanley (manufacturier), élection partielle de 1832, Montréal, 32, 4: 566 ss

Baie des Châteaux, poste de pêche, NouvelleFrance, 31, 2: 169

Baie des Esquimaux, poste de pêche, Nouvelle-France, 31, 2: 169

BAILLON (armateur de navires pour TerreNeuve), 40, 2: 197 ss

BAILLY DE MESSEIN, François-Augustin (marchand rural), Varennes (village), 33, 2: 215-262

Baleine, chasse à la, pêcheurs de Terre-Neuve, 39, 4: 534-539

Banalité, droit de, renforcement par les seigneurs, 36, 2: 176, 177; seigneuries Christie, Richelieu (vallée), 40, 4: 581; Séminaire de Saint-Sulpice, 36, 2: 252-256
Banque de Commerce canadienne, acquisition de la Banque des Cantons de l'Est, 38, 2: 177,178

Banque de Montréal, 36, 4: 545 ss

Banque de Québec, 36, 4: 543 ss

Banque des Cantons de l'Est, 38, 2: 165-179

Banqueroute, voir Faillite

Banques, investissemnents de Timothy Hibbard Dunn, 35, 3: 326 ss

Baptême, âge au, Nouvelle-France, 38, 3: 341 356

Baptêmes, marchands de Montréal, 33, 3: 441443; Nouvelle-France, 31, 1: 59-64; voir aussi Naissances

BARBEL, Marie-Anne (femme d'affaires), Nouvelle-France, 31, 2: 165-185

BARDY, Pierre-Martial (inspecteur d'écoles), Québec (province), 40, 4: 513, 515, 516

Bas Saint-Laurent, aménagement rural, 35, 2: 254-257

Basques, modalités d'engagement des pêcheurs, Nouvelle-France, 37, 4: 558 ss; pêcheries, Terre-Neuve, 39, 4: 532 ss

Batiscan, seigneurie, colonisation, NouvelleFrance, 40, 2: 163-191

Batterie de cuisine, artisans, Québec (ville) et Montréal, Nouvelle-France, 40, 3: 359, 361

BAZIL, Louis (négociant), Nouvelle-France, 31, 2: 168

Beaubassin, seigneurie, Acadie, NouvelleFrance, 37, 3: 405-410

BEAUCAGE, Azellus (syndicaliste), grève du textile, Lachute, 37, 2: 279 ss

Beauce, rang de la (paroisse Calixa-Lavallée), transmission des terres, 34, 3: 331-339

BEAUCOURS, Josué Dubois Berthelot de, voir DUBOIS BERTHELOT DE BEAUCOURS, Josué

BEAUDRY, Agapit-Charles [C. A.] (vicaire), émigration dans l'Ouest canadien, 33, 2: 169 ss

Beauharnois, seigneurie, commutation des terres, 36, 2: 171, 172, 178

Beaumont (paroisse), mariages exogames, Nouvelle-France, 35, 1: 4 ss

Beaumont, seigneurie, peuplement, NouvelleFrance, 39, 3: 392 ss

Beauport, asile psychiatrique, 39, 3: 345, 365 , 366

BÉCIGNEUL, Adolphe (actionnaire de la Compagnie de Colonisation et de Crédit des Cantons de l'Est), 32, 1: 22 ss 
BÉCIGNEUL, Eugène (actionnaire de la Compagnie de Colonisation et de Crédit des Cantons de l'Est), 32, 1: 22 ss

BÉCIGNEUL, Louis (actionnaire de la Compagnie de Colonisation et de Crédit des Cantons de l'Est), 32, 1: 22 ss

BÉDARD, Avila (sous-ministre des Terres et Forêts), système agro-forestier, 33, 1: 68

BÉDARD, Georges (travailleur), grève du textile, Lachute, 37, 2: 272 ss

BÉGON, Michel (intendant), gérance de la caisse de la Marine, Nouvelle-France, 32, 2: 185 ss; pêche au marsouin, NouvelleFrance, 37, 4: 544 ss

BÉLANGER, Arthur (médecin et député), suffrage féminin, 38, 1: 32

Belle-Isle, détroit de, pêcheries, NouvelleFrance, 31, 4: 494-499

BELNAP, Lamonte J. (directeur de la Consolidated Paper Corporation), 38, 2: 194, 195

BELVĖZE, Paul-Henry (commandant de La Capricieuse), 31, 3: 353-368

BERCUSON, David (historien), grève de Winnipeg, 37, 2: 170, 171, 178

BERKNER, Lutz (historien), histoire de la famille, 39, 2: 194

BERLINGUET, Joseph (maître-boulanger), faubourg Saint-Laurent (Montréal), 36, 2: $259-260$

BERNIER, Gérald (politicologue), effets de la Conquête, 39, 3: 369 ss

BERNIER, Joseph (ministre du Manitoba), écoles, 33, 1: 13 ss

BERTHELOT, Amable (homme politique), opposition aux bureaux d'enregistrement, $35,2: 220,221$

Berthier (comté), émigration vers les ÉtatsUnis, 38, 3: 414-422

Bibllothèque, diffusion de la littérature au Québec, 38, 4: 537, 538

Blbliothèque publique, Literary and Historical Society of Quebec, 35, 2: 188 ss

Bibliothèque scientifique, abbé Léon Provancher, 34, 4: 535-556

Biens mobiliers, voir Fortune mobilière

BIGOT, François (intendant), ferme de Tadoussac, Nouvelle-France, 31, 2: 172, 173; ouvrage de Guy Frégault, 35, 1: 61-62

Biographie, histoire littéraire du Québec, 38, 4: 527-530

BISSOT, François (marchand), tannerie-cordonnerie, Québec (ville), Nouvelle-France, 34, 3: 342 ss
BLANCHARD, Raoul (géographe), 31, 1: 4 ss; système agro-forestier, 33, 1: 69 ss

BLANCHET, François (médecin), réforme de la médecine, 34, 2: 223-244

Blé, commerce du, Bas-Richelieu (région), 38, 1: 5-21; seigneurie de Saint-Hyacinthe, 40, 3: 383, 384; régime seigneurial, Montréal, 36, 2: 241-262

Bleury, seigneurie, gestion des Christie, Richelieu (vallée), 40, 4: 563 ss

Bloc populaire canadien, René Chaloult, 39, 1: $37-46$

BLOCH, Marc (historien), École des Annales, 33, 3: 394-396

Board of Trade of Montreal, grève des charretiers, Montréal, 31, 3: 381, 388, 389

Bois, commerce du, entreprise de Timothy Hibbard Dunn, 35, 3: 323 ss; voir aussi Forêt

BOISHÉBERT, Henri-Louis Deschamps de (seigneur de Rivière-Ouelle), pêche au marsouin, Nouvelle-France, 37, 4: 548-553

BOISVERT, Réginald (journaliste), mutations de la Confédération des travailleurs catholiques du Canada, 34, 3: 378, 379

Bordeaux (France), commerce France/Nouvelle-France, 36, 3: 421-426; contrats de pêche, Terre-Neuve, 39, 4: 525 ss

BORDEN, Robert Laird (premier ministre du Canada), commissariat canadien à Paris, 34, 3: 366-370; conservateurs-nationalistes, 35 , 1: $33-54$

Botanique, abbé Léon Provancher, 34, 4: 536 ss; frère Marie-Victorin, 39, 1: 77-82

BOUCHARD, Gérard (historien), système agroforestier, 33, 1: $70 \mathrm{ss}$

BOUCHER DE BOUCHERVILLE, CharlesEugène (premler ministre du Québec), écoles du soir, 34, 4: 619 ss

BOUCHER DE LA BRUĖRE, Pierre (directeur du Courrier de Saint-Hyacinthe), écoles du soir, 34, 4: 614

BOUCHETTE, Joseph (arpenteur), fondateur de la Société pour l'encouragement des sciences et des arts au Canada, 35, 2: 181

Boulangerie, régime seigneurial, Montréal, 36 , 2: 256-261

BOULLONGNE, Barbe (épouse du gouverneur Louis d'Ailleboust), fondation de la confrérie de la Sainte-Famille, Nouvelle-France, 39, 4: 501

BOURASSA, Henri (homme politique), appui aux conservateurs-nationalistes, 35,1 : 
33 ss; nationalisme, $32,3: 358$ ss; suffrage féminin, 32, 1: 12-15

BOURGEOIS, Marguerite (religieuse), fondation de la congrégation des filles externes (confrérie), Nouvelle-France, 39, 4: 503

Bourgeoisie marchande, critique des sources, 38, 2: 203-222; marchands-négociants, Québec (ville), 36, 4: 527-551; pratiques foncières, Bas-Canada, 36, 2: 163-194; transition du féodalisme au capitalisme, 35,1 : 72 ss; $39,3: 370$ ss

BOURGET, Ignace (évêque de Montréal), division du clergé, 33, 4: 503 ss

BOURQUE, Gilles (sociologue), Rébellions de 1837-1838, 38, 2: 241, 242

BRAUDEL, Fernand (historien), École des Annales, 33, 3: 396-398

BRETEL, Louis (avocat-armateur), exemption des droits sur la morue, 36, 3: 335-337

British American Land Company, relations avec la presse, 31, 2: $245 \mathrm{ss}$; spéculation foncière, Cantons de l'Est, 36, 2: 185-190

British Colonist and St. Francis Gazette (journal), Stanstead, 31, 2: 239-243

Brown \& Childs (manufacturiers de chaussures), Montréal, 31, 2: 198-210

BROWN, Champion, voir Brown \& Childs

BROWN, Lewis H. (président de la Canadian Johns Manville), originès de la grève de l'amiante, 34, 3: 383

Bruck Silk Mill, grève du textile, Cowansville, 34, 2: 171-182

BRUNET, Michel (historien), 37, 4, 534; néonationalisme, 38, 2: 227, 235, 236

BRYDGES, Charles John (gérant du GrandTronc), grève des charretiers, Montréal, 31, 3: 381-393

BUCK, Tim (Parti communiste canadien), procès, 34, 1: 74-77

BUIES, Arthur (journaliste), rédaction de $L a$ Lanterne canadienne, 34, 2: 269-274

Bureau central des examinateurs catholiques, brevets d'enseignement, 36, 3: 353, 354

Bureau d'examinateurs, éducation, Québec (province), 40, 4: 524

Bureau de contrôle de la ville de Montréal, réforme municipale, 37, 2: 195, 196

Bureau de santé de la Cité de Montréal, hygiène publique, $36,4: 516$ ss; réforme, 35, 3: 362,363

Bureaux d'enregistrement, établissement des, débat et enquête de 1836, 35, 2: 217-230
C

CADET, Joseph (marchand), pêche à la morue, Nouvelle-France, 37, 4: 557-572; munitionnaire des troupes, approvisionnement de la Nouvelle-France, 36, 3: 414 ss

Calixa-Lavallée (village), transmission des terres, 34, 3: 331-339

Campagne, âge au baptême, Nouvelle-France, 38, 3: 347, 353, 354; conceptions prénuptiales, Nouvelle-France, 40, 2: 265-267; démographie différentielle, NouvelleFrance, 38, 3: 357-378; naissances illégitimes, Nouvelle-France, 40, 2: 242-244; recrutement du clergé, 37, 3: 380 ss

Canada Artistique (revue), voir Canada-Revue Canada Iron Foundries, Mauricie, 37, 1: 12

Canada, Le (journal), réforme de l'éducation, 36, 3: 348 ss

Canada-Revue (revue), conflit avec le clergé, 31, 4: 501-523

Canadian Patriot (journal), Stanstead, 31, 2: 249

Canadiens françals, marché du travail, 38, 2: 248,249 ; utilisation de l'asile psychiatrique, 39, 3: 363-365; voir aussi Émigration des Canadiens français

Cantons de l'Est, Banque des Cantons de l'Est, 38, 2: 165-179; colonisation et exploitation forestière, 32, 1: 19-39; industrie de l'amiante, 33, 2: 187-195; presse, 31, 2: 239-253; spéculation foncière par la British American Land Company, 36, 2: 185-190

CAOUETTE, Réal (homme politique), et René Chaloult, 39, 1: 45, 46

Capital américain, amiante et fer, Québec (province), 37, 4: $583 \mathrm{ss}$

Capital anglo-canadien, cuivre, Québec (province), 37, 4: 583 ss

Capital foncier, stratégie des habitants, BasCanada, 39, 4: 556 ss

Capitalisme, transition vers le, au Québec, 35, 1: 70 ss; 39, 3: 369-389

Capitalisme commercial, socio-économie du Québec, 35, 4: 503-508

Capitalisme industriel, Canada, 38, 2: 250253; socio-économie du Québec, 35, 4: 510 514

Capitaux françals, fuite après $1760,37,4$ : 603610 
Capricieuse, La (navire français), voyage au Canada, 31, 3: 351-370

"Carrefour», émission d'affaires publiques à la télévision de Radio-Canada, 36, 2: 214 ss

CARTIER Georges-Étienne (membre des Jeune-Canada), 40, 1, 21

CARTIER, Jacques I (marchand); Bas-Richelieu (région), 38, 1: $10 \mathrm{ss}$

CARTIER, Jacques II (marchand), Bas-Richelieu (région), 38, 1: 10 ss

CARTIER, Joseph II (marchand), Bas-Richelieu (région), 38, 1: 10 ss

CASGRAIN, Thérèse (femme politique), versement des allocations familiales aux mères, Canada, 40, 1: 93

Catholicisme, voir Clergé; Religion catholique

Catholicisme et nationalisme, Lionel Groulx, $32,3: 378-383$

Célibataires, conceptions prénuptiales, Nouvelle-France, 40, 2: 261-263; naissances illégitimes, Nouvelle-France, 40, 2: 247-250

Censure, émissions d'affaires publiques à la télévision de Radio-Canada, 36, 2: 228-237; littérature francophone du Québec, 38, 4: 539-541

Centre des femmes, avortement, $37,1: 82$ ss

Centre interuniversitaire de recherches sur les populations, 40, 1: 54; voir aussi Projet d'histoire sociale de la population $d u$ Saguenay

Certificats d'enregistrement de navires, Québec (ville), 35, 2: 231 ss

Cession des biens, droit de la faillite, BasCanada, 40, 2: 222 ss

CHALMERS, Don (délégué communiste), grève du textile, Cowansville, $34,2: 171$ ss

CHALOULT, René (homme politique), Québec (province), 39, 1: 25-50

Chambly, fort de, défense de la NouvelleFrance, 37, 1: 21-49

Chambly, seigneurie, peuplement, NouvelleFrance, 39, 3: 392 ss

Champlain (comté), agriculture, 35, 4: 549 ss

Champlain (paroisse), seigneurie de Batiscan, Nouvelle-France, 40, 2: 179 ss

CHAMPLAIN, Samuel de (explorateur), âge, 32, 2: 229-237; Gougou (monstre marin), 35, 3: 377; image de l'Amérindien, 39, 2: 263 ss; âge, 32, 2: 229-237

Chantiers maritimes, voir Construction navale

CHARBONNEAU, Hubert (démographe), démographie, Nouvelle-France, 33, 3: 434 ss; $38,3: 359,360$
CHARLEBOIS, Joseph (maître-boulanger), faubourg Saint-Joseph (Montréal), 36, 2: 258,259

Charlesbourg (paroisse), mariages exogames, Nouvelle-France, 35, 1: 4 ss

CHARLEVOIX, François-Xavier de (historien), tremblement de terre, Nouvelle-France, 36, 3: 375-387

CHARPENTIER, Alfred (président de la Confédération des travailleurs catholiques du Canada), 31, 2: 211-227

Charpentiers, Québec (ville), 31 , 4: 552-559

Charpentiers de navires, grève, Québec (ville), 37, 2: 227-239

Charretiers, grève à Montréal, 31, 3: 371-395

Chartres, Fort de (village), Illinois français, 39, 4: 586,589

CHASSEUR, Pierre, musée d'histoire naturelle, $31,1: 75,76$

Château Ramesay, Nouvelle-France, 37, 4: 605

Châtiments, voir Peines

CHAUNU, Pierre (historien), École des Annales, 33, 3: 396-398

CHAUSSEGROS DE LÉRY, Gaspard-Joseph (ingénieur), fort de Chambly, NouvelleFrance, 37, 1: 32 ss

Chaussure, industrie de la, Montréal, 31, 2: 187-210; syndicalisation des travailleurs, 36, 1: 77-105

CHAUVEAU, Pierre-Joseph-Olivier (surintendant de l'éducation), Québec (province), 40, 4: 529-531, 534

Cheminée, artisans, Québec (ville) et Montréal, Nouvelle-France, 40, 3: 358, 359

Chemins de fer, construction, travailleurs, Sherbrooke, 31, 4: 525-545

Cheptel, hiérarchie de la paysannerie, seigneurie de Saint-Hyacinthe, 40, 3: 392-396

Chevaliers de Saint-Crispin, Montréal, 31, 2: 208

Chevaliers du Travail, 37, 2, 187, 188; éducation des travailleurs, 34, 4: 600.ss

CHICOYNE, Jérôme-Adolphe (directeur de la Compagnie de Colonisation et de Crédit des Cantons de l'Est), 32, 1, 19-39

CHILDS, William Sullivan, voir Brown \& Childs

Chimie, industrialisation, Mauricie, $37,1: 8$ ss

CHRISTIE, Gabriel (militaire et seigneur), gestion des seigneuries, Richelieu (vallée), 40, 4: $561-582$ 
CHRISTIE, Napier Burton (seigneur), gestion des seigneuries, Richelieu (vallée), 40, 4: 563 ss

CHRISTIE, William Plenderleath (seigneur), gestion des seigneuries, Richelieu (vallée), 40, 4: 563 ss

Christieville (village), rentes seigneuriales, 40 , 4: 571

Circuits migratoires, migrants internes de Montréal, 35, 4: 532-534

Classe ouvrière, voir Travailleurs

Classes dominantes, historiographie, 38,2 : 223-243

Classes sociales, éducation, 32, 2: 159-179; Saguenay-Lac Saint-Jean, 31, 1: 19-25

Clergé, conflit avec la presse, 31, 4: 501-523; diocèse de Nicolet, 35, 3: 383-395; discours éducatif, 32, 2: 159-179; division sur la création d'une université à Montréal, 33, 4: $508 \mathrm{ss}$; émigration dans l'Ouest canadien, 33, 2: 163-185; intervention dans l'éducation, 40, 4: $506 \mathrm{ss}$; intervention dans les élections, 33, 4: 501 ss; Nouvelle-France, 31, 1: 50-54; opposition à la Ligue de l'Enseignement, 36, 3: 362-367; opposition au syndicalisme international, $36,1: 80 \mathrm{ss}$; origines et recrutement, 37, 3: 373-397; promotion des écoles du soir, 34, 4: $614 \mathrm{ss;}$ syndicats catholiques dans l'imprimerie, 37 , 2: $248-255$

Cléricalisation du personnel enseignant, venue au Québec des congrégations françaises, 36, 3: 406, 407

Cléricalisme, récits de voyage sur Paris, 550 ss:

Climat, âge au baptême, Nouvelle-France, 38 , 3: $350-354$

Clubs ouvriers municipaux, Montréal, 37, 2: $188 \mathrm{ss}$

Cogestion, Confédération des travailleurs catholiques du Canada, 34, 3: 381-384

COLBERT DE TERRON, Charles (intendant de marine), 37, 3: $433 \mathrm{ss}$

COLBERT, Jean-Baptiste (ministre), politiques coloniales, 37, 3: 431-452

Collaboration inter-syndicale, imprimerie, 37 , 2: $265-268$

Collège des Médecins et Chirurgiens, normalisation des études, $37,1: 52 \mathrm{ss}$; réforme, 35, 3: 359,360

Colloque d'histoire de 1963 à l'Université Laval, influence de l'École des Annales, 33, 3: 374
Articles par sujet

Colloque de Recherches sociographiques en 1962 à l'Université Laval, Influence de l'École des Annales, 33, 3: 368-374

Colonialisme, influence de l'Angleterre et de la France sur la Nouvelle-France, 35, 1: 70 ss

Colonie française (Nouvelle-France), pensée de Edmé Rameau de Saint-Père, 36, 1: $62 \mathrm{ss}$

Colonies anglo-américaines, pensée de Edmé Rameau de Saint-Père, 36, 1: 64 ss

Colonies espagnoles, pensée de Edmé Rameau de Saint-Père, 36, 1: 62

Colonisation, et âge au baptême, NouvelleFrance, 38, 3: 341-356; Cantons de l'Est, 32, 1: 19-39; influence sur l'exogamie, Nouvelle-France, 35, 1: 22 ss; Jean-Baptiste Colbert, 37, 3: 431-452; peuplement, Nouvelle-France, 39, 3: 391-405; Saguenay-Lac Saint-Jean, 38, 3: 379-408; seigneurie de Batiscan, Nouvelle-France, 40, 2: 163-191

Colonisation américaine, Illinois, 39, 4: 587589

Colonisation européenne, pensée de Edmé Rameau de Saint-Père, 36, 1: 55-74

Colonisation française, Illinois, $39,4: 583$ 591

COMBES, Émile (homme politique français), lutte contre les congrégations, 36, 3: 395, 396

COMEAU, Robert (historien), Parti communiste canadien, $37,2: 313$

Comité catholique du Conseil de l'Instruction publique, 36,3 : 369-371

Comité d'enquête de la Chambre d'Assemblée sur les pêcheries de Gaspé (1823), 36, 4: 492

Comité d'enquête sur l'industrie de la pêche (1851), Québec (province), 36, 4: 495

Comité de défense de Morgentaler, 37, 1: 83, 84

Comité de lutte pour l'avortement líbre et gratuit, 37, 1: 82-90

Comité provincial pour le suffrage féminin, Québec (province), 32, 1: 4 ss

Commerce, Nouvelle-France, 31, 2: 165-185; voir aussi Blé; Fourrures; Morue; Poisson

Commerce colonial, Jean-Baptiste Colbert, 37, 3: $440-452$

Commerce de détail, Bas-Richelieu (région), 38, 1: 13; Canada, 33, 4: 521-556; marchands-négociants, Québec (ville), 36, 4: 530-540 
Commerce de gros, marchands-négociants, Québec (ville), 36, 4: 530-540; relations avec le commerce de détail canadien, 33, 4: 532 ss

Commerce France/Nouvelle-France, Guerre de la Conquête, 36, 3: 413-426

Commerce hispano-américain, nombre de navires, 39, 4: 530

Commerce rural, François-Augustin Bailly de Messein, Varennes (village), 33, 2: 231 ss; marchands, L'Assomption (village), 39, 3: 327-329, 333

Commis des trésoriers généraux de la Marine, rôle et fonctions en NouvelleFrance, 32, 2: 186-190

Commissariat canadien, Paris, France, 34, 3: $357-376$

Commission d'enquête sur les problèmes constitutionnels (1956), Gaspésie, 36, 4: 502,503

Commission des relations ouvrières, grève du textile, Lachute, 37, 2: 273 ss

Commission des terres de Gaspé (1819), 36, $4: 491,492$

Commission Montpetlt (1930-1933), allocations familiales, Canada, 40, 1: 77, 78

Commission nationale du travail en temps de guerre (1944), allocations familiales, Canada, 40, 1: 76

Commission royale d'enquête sur le bilinguisme et le biculturalisme, André Laurendeau, 38, 1: 84-86

Commissions scolaires, Québec (province), 40, 4: 518 ss; réforme des, Ligue de l'Enseignement, 36, 3: 351-353

Commis-voyageurs, relations avec le commerce de détail canadien, 33, 4: 544-548

Common Law, droit de la faillite, 40, 2: 218, 219

Communautés religieuses, voir Congrégation

Communisme, implication dans la grève du textile à Cowansville, 34, 2: 171-182; lutte de l'École sociale populaire, 35, 4: 569 ss

Commutation des terres, Bas-Canada, 36, 2 : 167-173

Compagnie d'éclairage électrique de Québec et Lévis, investissemnents de Timothy Hibbard Dunn, 35, 3: 331, 332

Compagnie de colonisation et de crédit des Cantons de l'Est, 32, 1: 19-39

Compagnie de Guyane, Jean-Baptiste Colbert, 37, 3: 441, 442, 446
Compagnie de pouvoir électrique de Montmorency, voir Compagnie d'éclairage électrique de Québec et Lévis

Compagnie de pulpe de Chicoutimi, 31, 1: 24

Compagnie des Indes, colonisation allemande en Louisiane française, 33, 1: 53 ss

Compagnie des Indes Occidentales, JeanBaptiste Colbert, 37, 3: 445 ss

Compagnie des Indes Orientales, Jean-Baptiste Colbert, 37, 3: 442, 448, 449

Compagnies de commerce, Jean-Baptiste Colbert, 37, 3: 440-452

COMPĖRE, Marie-Madeleine (historienne), étude de l'alphabétisation, 39, 1: 61

Conceptions illégitimes ou prénuptiales, Nouvelle-France, 40, 2: 246-272; ville et campagne, Nouvelle-France, 38, 3: 372; voir aussi Naissances illégitimes

Concessions des terres, seigneurie de Batiscan, Nouvelle-France, 40,.2: 167-180; seigneuries Christie, Richelieu (vallée), 40, 4: 566-572

Concubinage, travailleurs, Sainte-Brigide (paroisse), 39, 2: 243, 244

Condition ouvrière, construction navale, Québec (ville), 37, 2: 230-232

Confédération des travailleurs catholiques du Canada, 34, 3: 377-405; développement, 37, 2: 206 ss; industrie de la chaussure, 36 , 1: 92-96; relations avec le gouvernement, 31, 2: 211-227

"Conférence de presse», émission d'affaires publiques à la télévision de Radio-Canada, 36, 2: 214 ss

Confessionnalité, éducation, Québec (province), 40, 4: 521, 522; enseignement, Québec (province), 32, 2: 161, 162

Confréries, gouvernement de Québec, Nouvelle-France, 32, 1: 84-88; 39, 4: 491-522

Congés de traite, commerce des fourrures, Nouvelle-France, $34,1: 7$ ss

Congrégation de la Vierge (confrérie), gouvernement de Québec, Nouvelle-France, 39, 4: 492 ss

Congrégation des filles (confrérie), gouvernement de Québec, Nouvelle-France, 39, 4: 492 ss

Congrégation des Jeunes Gens, travailleurs, Sainte-Brigide (paroisse), 39, 2: 243, 249

Congrégation Notre-Dame, congrégation des filles externes (confrérie), Nouvelle-France, $39,4: 503,518$ 
Congrégations françaises, venue au Québec, 36, 3: 389-411

Congrès des métiers et du travail du Canada, appui au Front populaire espagnol, 33, 4: 575-581; autonomie par rapport à 1'American Federation of Labor, 33, 4: 575-581; relations avec l'Union internationale des travailleurs en chaussures, $36,1: 81$ ss

Conquête, effets de la, 39, 2: 256; historiographie, 38, 2: 225; thèse de Maurice Séguin, 38, 4: 574-576; transition du féodalisme au capitalisme, 35, 1: 69-95; 39, 3: 369-389

Conquête, guerre de la, approvisionnement de la Nouvelle-France, 36, 3: 413-426; fuite des capitaux français, 37, 4: 603-610; oeuvre de Guy Frégault, 35, 1: 63-64; pêcheries de Gaspé, 37, 4: 565-569

CONROY, George (délégué apostolique), mission au Canada, 33, 4: 499-519

Conscription, émeutes, Québec (province), 37 , 1: 71-73; plébiscite, 39, 1: 37-39

Conseil d'Hygiène de la province de Québec, promotion de l'hygiène publique, 35,3 : $363 \mathrm{ss}$

Conseil de I'Instruction publique, 40, 4: 532534; comité catholique, 36, 3: 369-371

Conseil des Arts et Manufactures, écoles d'arts et métiers, 34, 4: 599 ss

Conseil législatif, enquête de 1836 sur le droit hypothécaire, $35,2: 217$ ss

Conseil national de recherches du Canada, histoire, indications bibliographiques, 35, 2: $201 \mathrm{ss}$

Conservateurs-nationalistes (groupe parlementaire), gouvernement de Robert Laird Borden, 35, 1: 33-54

Consolidated Paper Corporation, patronat, Mauricie, 38, 2: 193-195

Consommation du poisson, France, 39, 4: 546,547

Conspiration séditieuse (acte d'accusation), grève du textile, Lachute, 37, 2: 282 ss

Construction domiciliaire, Québec (ville), 31 , 4: 547-561

Construction ferroviaire, investissemnents de Timothy Hibbard Dunn, 35, 3: 327

Construction navale, grève des charpentiers, Québec (ville), 37, 2: 227-239; Québec (ville), 35, 2: 231-251; vallée du Saint-Laurent, $35,2: 237 \mathrm{ss}$

Contraception, discours médical, 38, 1:27; discours féministe, Québec (province), 37 , 1: 87
Contrats d'engagement, commerce des fourrures, Nouvelle-France, 34, 1: 3-26; liste d'engagés partis de Nantes, 33, 4: 583-586

Contrats de mariage, étude de l'alphabétisation, 39, 1: 54, 55

Contrats de société, commerce des fourrures, Nouvelle-France, 40, 3: 411-428

Contrats de travail, extension juridique, imprimerie, 37, 2: 257-264

Cooperative Commonwealth Federation, lien avec le Parti communiste canadien, 37, 2: 312,313

Coordination nationale pour l'avortement libre et gratuit, constitution, 37, 1: 85-90

Cordonnerie, Montréal, 31, 2: 187-210; Québec (ville), Nouvelle-France, 34, 3: 346 ss; voir aussi Chaussure

Corporatisme, Confédération des travailleurs catholiques du Canada, 31 , 2: 219-222; 34 , 3: 378-381; École sociale populaire, 35 , 4 : 580-583; syndicalisme catholique, 37,2 : 258-261

CORRY, Thomas (marchand), L'Assomption (village), 39, 3: 329, 335

Corvées obligatoires, droit de, renforcement par les seigneurs, 36, 2: 177

Coton, industrie du, Révolution industrielle, Angleterre, 39, 3: 381, 382

Coude, Le (établissement français), voir Moncton

Cour des sessions hebdomadaires, BasCanada, 38, 4: 509-511

Cour des sessions trimestrielles, Bas-Canada, 38, 4: 509-511

Cour du Banc du Roi, Bas-Canada, 38, 4: 508 ss

Cour martiale de 1838-1839, procès des Patriotes, 34, 1: 59 ss

Coutume de Paris, statut de la femme, 31, 2: $167 \mathrm{ss}$; transmission du patrimoine, 34, 3 : 331-339; 39, 4: 557

Cowansville, grève du textile à la Bruck Silk Mill, 34, 2: 171-182

CRAVEN, Paul (historien), syndicalisme au Canada, 37, 2: 179, 180

Créanciers, marchands-négociants, Québec (ville), 36, 4: 544-546

Crèche d'Youville, Soeurs Grises, Montréal, 40, 4: 537-559

Crédit, commerce de détail canadien, 33, 4: 537-544; marchands, L'Assomption (village), 39, 3: 331-341; marchands-négociants, Québec (ville), 36, 4: 540-550 
Crédit et prêts à la population, FrançoisAugustin Bailly de Messein, Varennes (village), 33, 2: $237 \mathrm{ss}$

Crédit social, René Chaloult et Réal Caouette, $39,1: 45,46$

CREIGHTON, Donald (historien), Conquête, 38, 2: 226, 227

Criminalité, Nouvelle-France, 31, 2: 229-238; répression, Bas-Canada, 38, 4: 499-521

Crise de 1929, syndicats de l'imprimerie, 37, 2: $255-264$

Crise économique de 1873, commerce de détail canadien, 33, 4: $548-554$

Cuir, artisans du, Québec (ville), NouvelleFrance, 34, 3: 341-356

Cuivre, industrie minière, Québec (province), 37, $4: 574$ ss

Culture, influence de l'organisation du territoire, 37, 3: 417-429; solidarités communautaires, 40, 1: 63, 69

Culture populaire, inventaire après décès, 38 , 2: 206

CURRAN, James (charretier), grève des charretiers, Montréal, 31, 3: 385, 388, 389

Cycle de la vie familiale, fortune de la paysannerie, seigneurie de Saint-Hyacinthe, 40, 3: 399-406; histoire de la famille, États-Unis, 39, 2: 194-199

\section{D}

DALHOUSIE, George Raimsay, comte de (gouverneur du Canada), fondateur de la Literary and Historical Society of Quebec, 35, 2: 180

DANCOSSE, Pierre, fils (habitant), pêche au marsouin, Nouvelle-France, 37, 4: 549-552

DANDURAND, Raoul (sénateur), légation canadienne à Paris, 34, 3: 373-375

DANSEREAU, Pierre (membre des JeuneCanada), 40, 1: 9 ss

DAUMARD, Adeline (historienne), inventaire après décès, $34,4: 518$ ss

Décès, marchands de Montréal, 33, 3: 441; Nouvelle-France, 31, 1: 59-64; voir aussi Sépultures

DECHÊNE, Louise (historienne), commerce des fourrures, Nouvelle-France, 34, 1: 3 ss; mariages, Nouvelle-France, 39, 2: 212 ss; recrutement du clergé, Nouvelle-France, 37 , 3: 390; transmission du patrimoine, Nouvelle-France, 39, 4: 557

Déchristianisation, récits de voyage sur Paris, $38,4: 550-563$

Déconfessionnalisation, Confédération des travailleurs catholiques du Canada, 34, 3: 387-391

Découvertes scientifiques et techniques, histoire des, indications bibliographiques, 35 , 2: 203 ss

Défense de la Nouvelle-France, fort de Chambly, 37, 1: 21-49

Défense navale canadienne de l'Empire britannique, contribution canadienne: débat sur la marine, $35,1: 43$ ss

DEGLER, Carl (historien), famille moderne, 39, 2: 207

Deléry, seigneurie, gestion des Christie, Richelieu (vallée), 40, 4: 563 ss

Délinquance, voir Criminalité

DEMERS, Jérôme (supérieur du Petit Séminaire de Québec), querelle autour du manuel sur la langue québécoise de l'abbé Thomas Maguire, 35, 3: 348 ss

Démocratie, Joseph-Édouard Turcotte, 38, 1: 63-68

Démocratie et humanisme, Confédération des travailleurs catholiques du Canada, 34, 3 : 384-387

Démocratisation, enseignement, Québec (province), 32, 2: 161 ss

Démographie, histoire de la famille, Europe, 39, 2: 163 ss; marchands de Montréal, 33, 3: 427-445; Montréal, 35, 4: 523-535; 40, 4: 551-556; Nouvelle-France, 31, 1: 49-73; registre de population de la NouvelleFrance, 38, 3: 423-426; Saguenay-Lac Saint-Jean, 31, 1: 7-10; 32, 1: 41-56; seigneurie de Batiscan, Nouvelle-France, 40 , 2: 180-183; ville et campagne, NouvelleFrance, 38, 3: 357-378; voir aussi Baptême(s); Centre interuniversitaire de recherches sur les populations; Conceptions illégitimes ou prénuptiales; Décès; Mariage(s); Mortalité; Naissances; Naissances illégitimes; Programme de recherche en démographie historique; Remariage; Sépultures

Déportation, Acadiens, 37, 3: 412-416

DEROME, Robert (historien de l'art), Charles Huot, 31, 3: 397 ss 
Deschambault, seigneurie, peuplement, Nouvelle-France, 39, 3: 392 ss

Développement régional, industrialisation, Mauricie, 37, 1: 3-19

Déviance, voir Criminalité

Devoir, Le (journal), appui aux Jeune-Canada, 40, 1: 10-12; condamnation de l'appui du Congrès des métiers et du travail du Canada au Front populaire espagnol, 33, 4: 579

Diarrhée, et mortalité, Montréal, 36, 4: 518, 519

DICKERSON, Silas Horton (rédacteur du British Colonist and St. Francis Gazette), 31, 2: $240-243$

Diffusion de la littérature, Québec (province), 38, 4: 533-539

Diffusion scientifique et technique, histoire, 35, 2: 214,215

Diphtérie, et mortalité, Montréal, 36, 4: 517, 518

Disciplines scientifiques, histoire des, indications bibliographiques, 35, 2: 202 ss

Discours médical, femme, 38, 1: 23-37

Dispenses de bans, mariages, NouvelleFrance, 35, 1: $23 \mathrm{ss}$

Distribution de marchandises, réseaux aux Canada, 33, 4: 521-556

Division du travail, construction navale, Québec (ville), 37, 2: 229, 230; industrie de la chaussure, Montréal, 31, 2: 191 ss; Montréal, $33,1: 44$ ss

Doctrine sociale de l'Église, promotion par l'École sociale populaire, 35, 4: 569 ss

Documents de la session, inventaire descriptif, $31,4: 563-574$

DOLLARD DES ORMEAUX, Adam, bataille du Long-Sault, Nouvelle-France, 35, 2: 164 ss

DOLLIER DE CASSON, François (sulpicien), interprétation de la bataille du Long-Sault, 35, 2: 166; récit de Rémy de Courcelles au Lac Ontario, Nouvelle-France, 32, 2: 242 ss

Dominion Textile, grève de 1937, 31, 2: 217

Donation entre vifs, transmission des terres, Calixa-Lavallée (village), 34, 3: 336 ss

Douaire coutumier, révision, débat et enquête de 1836, Bas-Canada, 35, 2: 222 ss

DRAPER, Patric M. (président du Congrès des métiers et du travail du Canada), appui au Front populaire espagnol, 33, 4: 580-581

Droit, aménagement du territoire, Gaspésie, 36, 4: 483-506; lois civiles françaises, Canada, $36,4: 486,487$
Droit canadien, faillite, Bas-Canada, 40, 2: 222-224

Droit criminel, Bas-Canada, 38, 4: 502-520

Droit de vote des femmes, voir Suffrage féminin

Droit français, faillite, 40, 2: 221

Droit hypothécaire canadien, révision, débat et enquête de 1836, Bas-Canada, 35, 2: 218 ss

Droit de gabelle, commerce de la morue, 36,3 : 329,330

Droits de propriété, Québec (province), 39, 2: 255, 257-259

Drolt seigneurial, voir Banalité, droit de; Corvée, droit de; Mouture, droit de; Réunion, droit de; Titre nouvel, droit de

DUBOIS BERTHELOT DE BEAUCOURS, Josué (ingénieur), fort de Chambly, Nouvelle-France, 37, 1:27 ss

DUBUC, Alfred (historien), influence de l'École des Annales, 33, 3: 377

DUBUC, Julien-Édouard-Alfred, entreprises, 31, 1: 24

DUMONT, Fernand (sociologue), «Actualité de Lionel Groulx», 32, 3: 354, 355; influence de l'École des Annales, 33, 3: 370 ss

Dunn and Company, voir DUNN, Timothy Hibbard

DUNN, Timothy Hibbard (commerçant de bois), diversification de ses activités économiques, 35, 3: 323-336

DUPLESSIS, Maurice (premier ministre du Québec), allocations familiales, 40, 1: 91 , 93; antisyndicalisme, 34, 3: 399 ss; biographie, 31, 3: 407-426; boycottage des émissions d'affaires publiques à la télévision de Radio-Canada, 36, 2: 229, 236; René Chaloult, $39,1: 27$ ss; grève du textile, Lachute, 37, 2: 284-289

DUPONT, René (secrétaire de la Société de rapatriement et de colonisation du Lac Saint-Jean), 38, 3: 386 ss

DUPUY, Claude-Thomas (intendant), gérance de la caisse de la Marine, 32, 2: 188 ss

Durham, enquête, écoles, Québec (province), 40, 4: 517; rappport, naissance de l'asile, Québec (province), 39, 3: 351, 352

DUROCHER, Jean-Baptiste (marchand), L'Assomption (village), 39, 3: 335, 342, 343 
$\mathbf{E}$

Eastern Townships Bank, voir Banque des Cantons de l'Est

Eau, hygiène publique, Montréal, 36, 4: 520, 521

Eau-de-vie, commerce de l', lien avec le tremblement de terre dans les récits, NouvelleFrance, 36, 3: 375-387

Éboulements, Les, seigneurie, peuplement, Nouvelle-France, 39, 3: 392 ss

Échantillonnage aléatolre, méthode, 37, 2: 307

École de formation sociale de Vaudreuil, oeuvre de l'École sociale populaire, 32, 2: 208,$209 ; 35,4: 575-577$

École de médecine, création, 34, 2: 238, 239; normalisation des études, 37, 1: 51-65

École de Montréal, Maurice Séguin, 38, 4: $570 \mathrm{ss}$

École des Annales, voir Annales, École des

École des Hautes études commerciales, Université de Montréal, 36, 1: 4 ss

École des sciences sociales, économiques et politiques, Université de Montréal, 36, 1: $6 \mathrm{ss}$

École néo-nationaliste, 38, 2: 226 ss

École sociale populaire, 32, 2: 203-228; 35, 4: 563-587

Écoles du Manitoba, crise scolaire, 33, 1: 3-23

Écoles du soir, éducation des travailleurs, 34, 4: 597-625; enfants, Québec (province), 38, 1: 42

Écoles ménagères, voir Ėnseignement ménager

Écoles normales, Ligue de l'Enseignement, $36,3: 353,354$

Économie agro-forestière, voir Système agroforestier

Économie marchande, R'as-Canada, 36, 2: 165-194

Économie, Québec (province), 39, 2: 253-261; effets de l'industrie minière, $37,4: 581-592$

Écossais, au Montreal Lunatic Asylum, 39, 3 : 363,364 ; travailleurs des chantiers ferroviaires, Sherbrooke, 31, 4: 535-537

Eddy, E.B., compagnie, grève à Hull, 32, 4: $604 \mathrm{ss}$

Édition critique, littérature francophone du Québec, 38, 4: 527-530
Éducation, famille/Église/État, France et Québec, 34, 2: 206 ss; idéologie conservatrice, 32, 2: 159-179; libéralisme, Québec (province), 40, 4: 505-535; congrégations enseignantes françaises, venue au Québec, 36, 3 : 389-411; réforme, Ligue de l'Enseignement, 36, 3: 339-373

Éducation civique, femmes, $32,1: 7$ ss

Éducation des filles, discours, 32, 2: 168 ss; France, 34, 2: 217, 218; Ligue de l'Enseignement, 36, 3: 360 ss

Éducation des travailleurs, écoles du soir, 34, 4: $597-625$

Église, Québec (province), 39, 1: 83-89; voir aussi Clergé; Religion catholique

Église de France, conflit entre ultramontains et jansénistes, 36, 2: $195 \mathrm{ss}$

Église d'Utrecht, dissidence avec l'Église de Rome, 36, 2: 209-212

Église/famille/État, éducation, France et Québec, 34, 2: 206 ss

Égoûts, système d', Montréal, 36, 4: 524

EID, Nadia Fahmy (historienne), éducation, Québec (province), 40, 4: 506, 507, 534

Élection partielle de 1832, Montréal, QuartierOuest, 32, 4: 565-584

Élections, intervention du clergé québécois, 33, 4: 501 ss

Électricité, Shawinigan Water and Power, Mauricie, 37, 1: 5 ss; 40, 1: 35 ss

Élite régionale, Banque des Cantons de l'Est, 38, 2: 165-179; Saguenay-Lac Saint-Jean, $39,1: 3-23$

Élite clérico-nationaliste, allocations familiales, Canada, 40, 1: 90-93

Élite québécoise, émigration dans l'Ouest canadien, 33, 2: 163-185

ELLICE, Edward (marchand et seigneur), commutation des terres seigneuriales, 36,2 : $171,172,178$

Émigration aux États-Unis, Canadiens français: $34,4: 557-567 ; 38,3: 409-422$; travailleurs canadiens, $36,1: 84$

Émigration des Canadiens français, ÉtatsUnis, 38, 3: 409-422; Nord de l'Ontario, 33, 2: 174 ss; Nouvelle-Angleterre, 34, 4: 557-567; Ouest canadien, 33, 2: 163-185

Encan, ventes à l', marchands-négociants, Québec (ville), 36, 4: 536, 537

Enclosures, voir Expropriation de la paysannerie

Endettement, marchands-négociants, Québec (ville), 36, 4: 546, 547; voir aussi Faillite 
Endettement paysan, L'Assomption (village), 39, 3: 331-341

Endogamie sociale, travailleurs, Sainte-Brigide (paroisse), 39, 2: 239-241

Enfance, histoire de la famille, Europe, 39, 2: 167

Enfants, abandon, Montréal, 40, 4: 537-559; illégitimité, Montréal, 40, 4: 540 ss; participation au marché du travail, États-Unis, 39 , 2: 200-202; travail et instruction obligatoire, Québec (province), 38, 1: 39-58; voir aussi Mortalité infantile

Enfants de Marie (congrégation), travailleurs, Sainte-Brigide (paroisse), 39, 2: 243, 249

Engagement, contrats d', commerce des fourrures, Nouvelle-France, 34, 1: 3-26; liste d'engagés partis de Nantes, 33, 4: 583-586

English Cathedral (paroisse, ville de Québec), alphabétisation, 39, 1: 63-76

Engrais, seigneurie de Saint-Hyacinthe, 40, 3: 386

Enseignement, voir aussi Éducation

Enseignement agricole, écoles primaires, Ligue de l'Enseignement, 36, 3: 357 ss

Enseignement ménager, Ligue de l'Enseignement, 36, 3: 361 ss

Enseignement primaire, réforme de l', Ligue de l'Enseignement, 36, 3: 348 ss

Enseignement scientifique, indications bibliographiques, 35, 2: 199 ss

Enseignement supérieur francophone, réforme, Québec (province), 36, 1: 4 ss

Enseignement technique, écoles secondaires, Ligue de l'Enseignement, 36, 3: 358 ss

Entomologie, abbé Léon Provancher, 34, 4: 539 ss

Épidémie (1885), variole, Montréal, 36, 4: 517; influence sur l'exogamie, Nouvelle-France, $35,1: 17 \mathrm{ss}$

Épiscopat, dissidence avec l'Église de Rome, 36, 2: 209-212

Esclavage, pensée de Edmé Rameau de SaintPère, 36, 1: 60, 61

Esthétique, littérature francophone du Québec, $38,4: 543-546$

ESTRADES, Godefroi-Louis, comte d' (conseiller de Jean-Baptiste Colbert), 37, 3: 435 ss

Estrie, voir Cantons de l'Est

État, intervention dans l'éducation, Québec (province), 40, 4: $513 \mathrm{ss;} \mathrm{rapport} \mathrm{avec} \mathrm{la}$ science, 35, 2: 213
État/famille/Église, éducation, France et Québec, 34, 2: $206 \mathrm{ss}$

État-providence, programme d'allocations familiales, Canada, 40, 1: 73-95

États-Unis, histoire de la famille, 39, 2: 185209; immigration des Canadiens français, 34, 4: 557-567; 38, 3: 409-422; immigration des travailleurs canadiens, $36,1: 84$

Ethnicité, alphabétisation, Québec (ville), 39, 1: 64, 72; créanciers des marchands-négociants, Québec (ville), 36, 4: 548-550; marchands, L'Assomption (village), 39, 3: 326, 327; marché du travail, Canada, 38, 2: 247250; mariages, travailleurs, Sainte-Brigide (paroisse), 39, 2: 241; Montreal Lunatic Asylum, 39, 3: 363-365; mortalité, Montréal, 36, 4: 508 ss; travailleurs de l'Alcan, Saguenay, 37, 2: 297-304

Exogamie, gouvernement de Québec, Nouvelle-France, 35, 1: 3-32; Nouvelle-France, Nouvelle-Orléans, Saint-Domingue, 39, 2: 224-230

Exploitation familiale, seigneurie de Saint-Hyacinthe, 40, 3: 381 ss; solidarités communautaires, 40, 1: 60-65

Exploitation forestière, Cantons de l'Est, 32, 1: $19-39$

Exploitation minière, technologies, 37, 4: 574581

Exportation, blé de Montréal, régime seigneurial, 36, 2: 242-249; industrie minière, Québec (province), 37, 4: 582, 583; navires construits à Québec, 35, 2: 246 ss

Expropriation de la paysannerie, Angleterre, $39,3: 375-379$

Extraction minière, voir Exploitation minière

$\mathbf{F}$

FABRE, Édouard-Charles (archevêque de Montréal), conflit avec Canada-Revue, 31, 4: 501 ss; vocation religieuse, 37, 3: 392

FABRE, Hector (commissaire canadien à Paris), 34, 3, 358-363

Faillite, droit de la, Bas-Canada, 40, 2: 215235; commerce de détail canadien, 33, 4 : 548-554

FALARDEAU, Jean-Charles (sociologue), influence de l'École des Annales, 33, 3: 
370 ss; mutations de la Confédération des travailleurs catholiques du Canada, 34, 3: 378

Famille, caractéristiques, Nouvelle-France, 38, 3: 363-366; histoire de la, États-Unis, 39, 2: 185-209; historiographie, Europe, 39, 2 : 163-184; inventaire après décès, 38, 2: 204 206; patrimoine foncier, Québec (région), 39, 4: 573, 574; peuplement, NouvelleFrance, 39, 3: 398-400, 404; programme d'allocations familiaies, Canada, 40, 1: 73 95; reconstitution, Saguenay-Lac Saint-Jean, $31,1: 8 ; 32,1: 50$ ss; solidarités communautaires, 40, 1: 53-71; taille, marchands de Montréal, 33, 3: $434 \mathrm{ss;}$ théories de la: 34, 2: 197-207; travailleurs, Sainte-Brigide (paroisse), 39, 2: 242-247

Famille/Église/État, éducation, France et Québec, 34, 2: 206 ss

Farine, voir Blé

Farmer's Advocate and Townships Gazette (journal), Sherbrooke, 31, 2: 247, 248

FAVERY, Marie (épouse de Pierre Le Gardeur de Repentigny), fondation de la confrérie du Rosaire, Nouvelle-France, 39, 4: 497

Fécondité, voir Naissances

Fédération canadienne des cordonniers, 36 , 1: $81-89$

Fédération catholique des métiers de l'imprimerie du Canada, 37, 2: 255 ss

Fédération des unions internationales des métiers de l'imprimerie, 37, 2: 265-267

Fédération des unions industrielles du Québec, collaboration avec la Confédération des travailleurs catholiques du Canada, 34, 3: 395,396

Fédération internationale des syndicats ouvriers, appui au Front populaire espagnol, 33, 4: 576-578

Fédération internatlonale des ouvriers unis des textiles d'Amérique, grève de Lachute, 37, 2: 271 ss

Fédération nationale Saint-Jean-Baptiste, suffrage féminin, 32, 1: 3-18; syndicalisme féminin, 32, 4: 613, 614

Féminisme, lien avec le nationalisme de Lionel Groulx, 32, 3: 394-398; lutte pour le droit à l'avortement, Québec (province), 37, 1: 8190

Femmes, alphabétisation, Québec (ville), 39, 1: 63 ss; discours médical, 38, 1: 23-37; droit de vote, Québec (province), 32, 1:3-
18; histoire de la famille, Europe, 39, 2:

176-178; image de la femme chez Lionel Groulx, 32, 3: 385-398; participation au marché du travail, États-Unis, 39, 2: 200202; syndicats catholiques à Hull, 32, 4: 603-628

Femmes d'affaires, Marie-Anne Barbel, Nouvelle-France, 31, 2: 165-185

Féodalisme, Bas-Canada, 36, 2: $166 \mathrm{ss;} \mathrm{transi-}$ tion ver le capitalisme au Québec, 35,1 : 70 ss; 39, 3: 369-389

Féodalité, pensée de Edmé Rameau de SaintPère, $36,1: 58,64,65$; répression du crime, 38, 4: 500 ss

Fer, industrie minière, Québec (province), 37, 4: 575 ss

FERLAND, Jean-Baptiste-Antoine (historien), naissances illégitimes, Nouvelle-France, 40 , 2: 240

Fiançailles et sexualité, Nouvelle-France, 40 , 2: 269

FILIATREAULT, Aristide (rédacteur de la Canada-Revue), 31, 4: 507-523

Filles-mères, Nouvelle-France, 40, 2: 247-250; voir aussi Naissances illégitimes

Finlandais, immigration au Québec, 38, 3: 400, 401

Fiscalité, commerce de la morue, Terre-Neuve/ France, 36, 3: 323-338

FISHER, James (médecin), réforme de la médecine, 34, 2: 225, 226

Fleury, seigneurie (Saint-Joseph de Beauce), peuplement, Nouvelle-France, 39, 3: 392 ss

Foin, seigneurie de Saint-Hyacinthe, 40, 3: 384,385

Folie, voir Asile psychiatrique

Folk society, Québec (province), 38, 2: 230, 231

Fonctionnalisme, théories de la famille, 34, 2 : 197 ss

Forêt, Gaspésie, 36, 4: 500-503; historiographie, 33, 1: 67-78; seigneuries Christie, Richelieu (vallée), 40, 4: 577-581; voir aussi Exploitation forestière; Système agro-forestier

Formation des maîtres, réforme, Ligue de l'Enseignement, 36, 3: 353 ss

FORNEL, Jean-Louis (négociant), NouvelleFrance, 31, 2: 166-170

FORNEL, veuve, voir BARBEL, Marie-Anne

FORSEY, Eugene A. (sénateur), syndicalisme au Canada, 37, 2: 168, 169 
FORTIN, Gérald (sociologue), système agroforestier, 33, 1: $68 \mathrm{ss}$

Fortune, artisans, Québec (ville) et Montréal, Nouvelle-France, 40, 3: 339-372; hiérarchie de la paysannerie, seigneurie de Saint-Hyacinthe, 40, 3: 397-406; marchands, L'Assomption (village), 39, 3: 329-331

Fortune immobilière, artisans, Québec (ville) et Montréal, Nouvelle-France, 40, 3: 352-354

Fortune mobilière, artisans, Québec (ville) et Montréal, Nouvelle-France, 40, 3: 343 ss; patrimoine foncier, Québec (région), 39, 4: 574-576

Fosses d'aisance, et mortalité, Montréal, 36, 4: 523,524

FOUQUET, Nicolas (surintendant des Finances), France, 37, 3: $433 \mathrm{ss;}$

Fourrures, commerce des, engagements, Nouvelle-France, 34, 1: 3-26; Micmacs, Nouvelle-France, 37, 3: 403, 405, 406; Nouvelle-France, 39, 2: 254, 255; pêcheurs de Terre-Neuve, 39, 4: 536-539; sociétés, Nouvelle-France, 40, 3: 409-428

Franc et commun soccage, tenure en, attitudes de la bourgeoisie marchande, BasCanada, 36, 2: 166 ss

France, aménagement rural en régions défavorisées, 35, 2: 257-259; histoire de, conception de Lionel Groulx, 34, 2: 247 ss; histoire de la famille, 39, 2: 163 ss; investissements dans les Cantons de l'Est, 32, 1: 19 ss; recrutement du clergé, $37,3: 376$ ss; relations avec le Canada, 31, 3: 351-370; 34, 3: 357-376; 38, 4: 542, 543; société rurale, mariages exogames, $35,1: 7$ ss

France/Antilles/Nouvelle-France, commerce de la morue, $37,4: 558,559$

FRANCHÈRE, Timothée (marchand), BasRichelieu (région), 38, 1: 11 ss

Franciscain, Tiers ordre (confrérie), gouvernement de Québec, Nouvelle-France, 39, 4: 492 ss

Franco-Américains, lieux d'origine, 38,3 : 409-422; messianisme, 34, 4, 557-567; rapatriement, Saguenay-Lac Saint-Jean, 38, 3: $379-408$

FRANCOEUR, Louis (journaliste), appui aux Jeune-Canada, 40, 1: 14-16

FRÉGAULT, Guy (historien), 37, 4, 534; néonationalisme, $38,2: 226,227$; notice nécrologique, 31 , 3: 323; oeuvre sur Lionel Groulx, 36, 4: 569-582; présentation de son oeuvre, $35,1: 55-68$
Fréquentation scolaire, Ontario et Québec (province), 38, 1: 47-49

Fréquentations, période des, Nouvelle-France, 40, 2: 270

Fret, commerce de la morue, Terre-Neuve/Marseille, 40, 2: 195, 208-210

Front commun pour l'abrogation des lois sur l'avortement, 37, 1: 83, 84

Front de libération des femmes, avortement, 37, 1: $82 \mathrm{ss}$

Front populaire espagnol, appui du Congrès des métiers et du travail du Canada et de la Fédération internationale des syndicats ouvriers, 33, 4: 575-581

FRONTENAC Louis de Buade, comte de (gouverneur), oeuvre de Guy Frégault, 35, 1: 60-61

G

Gabelle, droits de, commerce de la morue, 36, 3: 329,330

GAGNON, Jacques (habitant), pêche au marsouin, Nouvelle-France, 37, 4: 545 ss

Galerie de Peinture de Québec, La, 31, 1: 75, 76

Garderie, Soeurs Grises de Montréal, 34, 1: 27 55

GARNEAU, François-Xavier (historien), influence sur Lionel Groulx, 32, 3: 347-350

Garnison, fort de Chambly, Nouvelle-France, 37, 1: 42-45; Québec (ville), NouvelleFrance, 32, 4: 535-563

Gaspé, seigneurie, peuplement, NouvelleFrance, 39, 3: 392 ss

Gaspé, pêcheries, $36,4: 485$ ss; 37 , 4: 565-659

Gaspésie, histoire juridique, 36, 4, 483-506

GAUDRY, Julie (Soeur Grise de Montréal), fondation et direction des salles d'asile, 34 , 1: 29 ss

GAUTHIER, Georges (archevêque de Montréal), suffrage féminin, $32,1,6$ ss

GAUTHIER, Pierre (médecin et député), suffrage féminin, 38, 1, 32, 33

GAUVIN, François (habitant), pêche au marsouin, Nouvelle-France, 37, 4: 545-551

Gens de Mer (tribu amérindienne), voir Ouinipigous 
GÉRIN-LAJOIE, Marie Lacoste (féministe), suffrage féminin, 32, 1: 3-18

GODBOUT, Adélard (premier ministre du Québec), et René Chaloult, 39, 1: 33 ss; Ordre de Jacques-Cartier, 40, 2: 284, 285, 287

GODBOUT, Archange, o.f.m. (archiviste), répertoire généalogique, $38,3: 361,362$

Goélette, construction navale, vallée du SaintLaurent, 35, 2: 238 ss; navigation sur le Richelieu, 38, 1: 16-20

GOODY, Jack (anthropologue), histoire de la famille, Europe, 39, 2: 169 ss

GOSSELIN, Émile, systè̀me agro-forestier, 33, 1: $68 \mathrm{ss}$

GOUBERT, Pierre (historien), École des Annales, 33, 3: 396-398

GOUDIE, John (négociant), fortune, 38,2 : 209, 210; Québec (ville), 36, 4: 531 ss

Gougou (monstre marin), Kokotché des Algonquiens, 35, 3: 377-381

GOUIN, Lomer (premier ministre du Québec), réforme de l'éducation, 36, 3: 366-372

GOUIN, Paul (homme politique), chef de l'Action libérale nationale, $39,1: 27 \mathrm{ss}$

Goutte de lait (association), pasteurisation du lait, Montréal, 36, 4: 522, 523

Gouvernement responsable, patriotes et réformistes, 33, 1: 25-37

Grande Côte (rang), seigneurie de Batiscan, Nouvelle-France, 40: 2: 169 ss

Grande-Bretagne, voir Angleterre

Grand-Tronc, chemin de fer du, grève des charretiers, Montréal, 31, 3: 371-395

GRANT, William (conseiller législatif), lotissement du quartier Saint-Roch, Québec, 34, 4: 582 ss

Granville (France), armateurs de navires pour Terre-Neuve, 40, 2: 195 ss

Gratuité scolaire, écoles du soir, 34, 4: 609 ss; Ligue de l'Enseignement, 36, 3: 350, 351

GRAVÉ DU PONT, François (capitaine de navire), Nouvelle-France, 32, 2: 229 ss

GREENWAY, Thomas (premier ministre du Manitoba), écoles, $33,1: 5$ ss

GREER, Allan (historien), hiérarchie de la paysannerie, 40, 3: 377

Grèves, charpentiers de navires, Québec (ville), 37, 2: 227-23'; charretiers, Montréal, 31, 3: 371-395; Mouvement des 44 heures, imprimerie, 37, 2: 242-251; nombre de, Québec (province) et Ontario, 37, 2: 213-220; textile, Ayers, Lachute, 37, 2:
271-289; textile, Bruck Silk Mill, Cowansville, 34, 2: 171-182; textile, Dominion

Textile, 31, 2: 217

Grossistes, voir Commerce de gros

GROULX, Lionel (historien), 32, 3: 325-346; appui aux Jeune-Canada, 40, 1: 7 ss; bibliographie, 32, 3: 465-523; carrière d'historien, 32, 3: 409-413; René Chaloult, 39, 1: 27 ss; conception de l'histoire, 32, 3: 347$356,361,362$, 413-425; idéologie, 32, 3 : 435-448; image de la femme, 32 , 3: 385398; influence politique, $32,3: 362-384$; interprétation de l'histoire canadienne, 32 , 3: 425-433; nationalisme, 32, 3: 364-384, 449-464; oeuvre de Guy Frégault, 35, 1 : 65 ss; 36,4 : 569-582; querelle autour de son roman L'Appel de la race, 32, 3: 399405; questions internationales, 34, 2: 245 255; Rébellions de 1837-1838, 38, 2: 234

Groupe de recherche sur les idéologies et la société canadienne-française, historiographie québécoise, 33, 3: 382, 383

Groupes socio-professionnels, alphabétisation, Québec (ville), 39, 1: 66 ss

GUÉROUT, Pierre (marchand), Bas-Richelieu (région), 38, 1: 11 ss

Guerre, influence sur l'exogamie, NouvelleFrance, 35, 1: $17 \mathrm{ss}$; technique de, fort de Chambly, Nouvelle-France, 37, 1: 21-49

Guerre d'Indépendance américaine, voir Révolution américaine

Guerre de la Conquête, voir Conquête, Guerre de la

Guerre iroquoise, mortalité française, Nouvelle-France, 36, 1: 31-54

GUIBORD, Joseph (typographe), violence lors de l'inhumation, 37, 1: 75, 76

Guyane, Jean-Baptiste Colbert, 37, 3: 440 ss

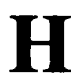

Habitant, image-type, Bas-Canada, 39, 4: 553, 554; stratégie foncière, Québec (région), 39, 4: 551-581

Habitation, artisans, Québec (ville) et Montréal, Nouvelle-France, 40, 3: 346-352

Hagiographie, mentalité religieuse populaire au Québec, 35, 2: 263-267 
HAJNAL, John (démographe), histoire de la famille, Europe, 39, 2: 165

Hall, moulins (Montmorency), investissements de Timothy Hibbard Dunn, 35, 3: 330

HAMEL, Philippe (homme politique), Québec (province), 39, 1:27 ss

HAMELIN, Jean (historien), influence de l'École des Annales, 33, 3: 373 ss

HARDY, Blanche (mère d'André Laurendeau), 38, 1: 78-80

HAREVEN, Tamara (historienne), FrancoAméricains, 38, 3: 412

HARVEY, Fernand (historien), historiographie de la Revue d' histoire de l'Amérique française, 36, 4: 553 ss

Hautes études commerciales, École des, Université de Montréal, 36, 1: 4 ss

HAVY, François (négociant), Nouvelle-France, 31, 2: 168

HAZEUR, François (entrepreneur), pêche au marsouin, Nouvelle-France, 37, 4: 544-547

HENEKER, Richard William (homme d'affaires), Banque des Cantons de l'Est, 38, 2: $169 \mathrm{ss}$

HENRIPIN, Jacques (démographe), démographie, Nouvelle-France, 33, 3: 428 ss

HENRY, Edme (notaire), gestion des seigneuries Christie, Richelieu (vallée), 40, 4: 564

HENRY, Louis (démographe), histoire de la famille, Europe, 39, 2: 165, 166

Henryville (village), rentes seigneuriales, 40, 4: 571

HICHÉ, Henri (notaire), lotissement du quartier Saint-Roch, Québec, 34, 4: 572 ss

Histoire, objet et méthode, 33, 3: 388-394; promotion par la Literary and Historical Society of Quebec, 35, 2: 186 ss; sens de 1': JeanPierre Wallot, 37, 4: 533-542

Histoire des idéologies, liens avec l'histoire des sciences, 35, 2: 211, 212

Histoire économique, liens avec l'histoire des sciences, 35, 2: 209-210

Histoire naturelle, bibliothèque de l'abbé Léon Provancher, 34, 4: 535-556; conférences et publications par la Literary and Historical Society of Quebec, 35, 2: 186 ss; musée, $31,1: 75,76 ; 35,2: 190$ ss

Histoire sociale, liens avec l'histoire des sciences, 35, 2: 212, 213

Historiographie, $19 \mathrm{e}$ siècle canadien, 33,3 : 402-419; classes dominantes, 38, 2: 223 243; famille, Europe, 39, 2: 163-184; hié- rarchie de la paysannerie, Québec (province), 40, 3: 375-379; littérature francophone du Québec, 38, 4: 523-547; Parti communiste canadien, 37, 2: 309-319; Revue d' histoire de l'Amérique française, 1972-1981, 36, 4: 553-567; sciences et techniques au Canada, 35, 2: 193-215; syndicalisme québécois, 37, 2: 201-204; système agro-forestier, 33, 1: 67-78

Historiographie canadienne-anglaise, syndicalisme au Canada, 37, 2: 165-184

Historiographie québécoise, évolution, 33, 3: 357-386

HOCQUART, Gilles (intendant), gérance de la caisse de la Marine, Nouvelle-France, 32, 2: 182 ss

Hollande, commerce colonial français, 37, 3: 445-447

HOMEL, Gene (historien), syndicalisme au Canada, 37, 2: 180

Hommes, alphabétisation, Québec (ville), 39, 1: 63 ss

Hommes d'affaires, Saguenay-Lac Saint-Jean, $39,1: 7$ ss

Hommes d'entreprise, direction des entreprises, 38, 2: 184 ss

Homogamie, Nouvelle-France, NouvelleOrléans, Saint-Domingue, 39, 2: 224-226

Hôpital général de Québec, soin des malades mentaux, 39, 3: 348, 349

Hospitalisation militaire, Hôtel-Dieu de Québec, Nouvelle-France, 32, 4: 544-546

Hôtel-Dieu de Québec, hospitalisation militaire, Nouvelle-France, 32, 4: 544-546; Nouvelle-France, 31, 1: 29-47

HOUDAILLE, Jacques (démographe), démographie, Saint-Domingue, 39, 2: 218, 222, 225

HUDON, Léonidas (jésuite), fondateur de l'École sociale populaire, 35, 4: 563, 564

Hull, syndicalisme catholique, 32, 4: 603-628

HUOT, Charles (peintre), peintures à l'Assemblée nationale, 31, 3: 397-405

Hurons (tribu amérindienne), motivations à la bataille du Long-Sault, Nouvelle-France, 35, 2: 166 ss

HURTUBISE, Pierre (historien), origine sociale du clergé, 37, 3: 382, 389, 390

Hygiène publique, Montréal, 36, 4: 507-526; réformes entreprises par les médecins francophones, 35, 3: 361 ss; services, 34, 2: 240-242 
Hypothèque, révision du droit hypothécaire canadien, 35, 2: $218 \mathrm{ss}$; prêts hypothécaires, 35, 3: 325 ss

I

IBERVILLE, Pierre LeMoyne d' (explorateur), oeuvre de Guy Frégault, 35, 1: 57-60

Iconographle, Amérindiens, Nouvelle-France, 39, 2: 263-270

"Idées en marche, Les", émission d'affaires publiques à la télévision de Radio-Canada, 36, 2: 214 ss

Illégitimité, enfants, Montréal, 40, 4: 540 ss; voir aussi Conceptions illégitimes ou prénuptiales; Naissances illégitimes

Illinois, colonisation française, 39, 4: 583-591

Immigrantes, conceptions prénuptiales, Nouvelle-France, 40, 2: 264

Immigrants, allocations familiales, Canada, 40, 1: 88; travailleurs de l'Alcan, Saguenay, 37, 2: $297-304$

Immigration, mariages, Nouvelle-France, Nouvelle-Orléans, Saint-Domingue, 39, 2: 224230; naissance de l'asile, 39, 3: 351, 362 , 363; peuplement, Nouvelle-France, 39, 3: 396, 397; population de Montréal, 35, 4: 526-527; rôle de la parenté, États-Unis, 39, 2: 192, 193; Saguenay-Lac Saint-Jean, 38, 3: $387-406$

Importation, marchandises en magasin, Québec (ville), 36, 4: 533-535

Imprimé, histoire de l', lien avec l'histoire littéraire, 38, 4: 533-539

Imprimerie, syndicats catholiques et unions internationales, 37, 2: 241-269

Incorporation civile, congrégations françaises, 36, 3: 391-397

Indépendance (Québec, province), Guy Frégault, 36, 4: 574-582; Jeune-Canada, 40, 1 : 23; Lionel Groulx, 36, 4: 574-582; Maurice Séguin, 38, 4: $578 \mathrm{ss}$

Industrialisation, Canada, 38, 2: 250-253; chaussure, Montréal, 31, 2: 187-210; histoire de la famille, 39, 2: $186 \mathrm{ss}$; histoire de la famille, Europe, 39, 2: 171-173; impact sur l'abandon des enfants, 40, 4: 538 ss; Mauricie, 37, 1: 3-19; 40, 1: 29-50; nais- sance de l'asile psychiatrique, 39, 3: 348, 350, 351; Québec (province), 36, 3: 340, $341 ; 39,2: 260 ; 40,2: 276,277,282$;

Saguenay, 37, 2: 291, 292; Saguenay-Lac Saint-Jean, 31, 1: 11, 12; travail des enfants, Québec (province), 38, 1: 52, 53, 56

Industrie minière, amiante, 33, 2: 187-195; Québec (province), 37, 4: 573-602

Industries et manufactures, investissemnents de Timothy Hibbard Dunn, 35, 3: 332-334

Injures verbales, Nouvelle-France, 31, 2: 229238

Inspecteurs d'écoles, Québec (province), 40, 4: 526-528

Instituteurs et institutrices, salaires des, Québec (province), 36, 3: 352

Institutionnalisme, socio-économie du Québec, 35, 4: 483-521

Instruction obligatoire, Ligue de l'Enseignement, 36, 3: 350, 351; opposition, 32, 2: 174 ss; travail des enfants, Québec (province), 38, 1: 39-58

Instruction publique, ministère de l', FélixGabriel Marchand, 36, 3: 341, 342

Insurrection appréhendée, procès politiques canadiens, 34, 1: 57-93

Intégration horizontale, industrialisation, Mauricie, $37,1: 4$ ss

Intégration verticale, industrialisation, Mauricie, $37,1: 4$ ss

Internationalisation, industrie minière, 37,4 : 578,579

Interventions armées, histoire du Québec, 37, 1: $67-79$

Inuit, allocations familiales, Canada, 40, 1: 87; Labrador, Nouvelle-France, 31, 4: 481-499

Inventaire en magasins, marchands-négociants, Québec (ville), 36, 4: 530-540

Inventaires après décès, étude des marchands, 38, 2: 204-208; Notre-Dame de Québec (paroisse), 34, 4: 515-533; stratégie foncière des habitants, Québec (région), 39, 4: 562565

Investissements américains, industrie de l'amiante, 33, 2: 191 ss

Investissements britanniques, industrie de l'amiante, 33, 2: 190

Irlandais, élection partielle de 1832, Montréal, 32, 4: 572-574; marché du travail, Canada, 38, 2: 249, 250; Montreal Lunatic Asylum, $39,3: 363,364$; travailleurs des chantiers ferroviaires, Sherbrooke, 31, 4: 535-537 
Iroquois (tribu amérindienne), guerre et mortalité française, Nouvelle-France, 36, 1: 3154; motivations à la bataille du Long-Sault, Nouvelle-France, 35, 2: 163 ss

Itinéraire individuel, histoire de la famille, États-Unis, 39, 2:-195-199

$\mathbf{J}$

JACOBS, Samuel (marchand), Bas-Richelieu (région), 38, 1:9 ss

JAKOBSON, Roman (linguiste), schéma de la communication, 38, 4: 526

Jansénisme, conflit dans l'Église de France, 36, 2: 195 ss

Jésultes, appui aux Jeune-Canada, 40, 1:9, 10, 12; conflit avec les prêtres des Missions Étrangères en Louisiane, 36, 2: 202-204; congrégation de la Vierge (confrérie), Nouvelle-France, 39, 4: 499 ss; fondateurs de l'École sociale populaire, 32, 2: 203 ss; Nouvelle-France, 31, 1: 51; seigneurie de Batiscan, Nouvelle-France, 40, 2: 173-175

Jeune-Canada, 40, 1: 5-28

Jeunes Gens, congrégation des, travàilleurs, Sainte-Brigide (paroisse), 39, 2: 243, 249

Jolie Galère, La (navire français), transport de pacotille, 36, 3: 420, 421

JOLIETTE, Barthélémy (seigneur), seigneurie de Lavaltrie, 36, 2: 178, 179

Journal d'Hygiène populaire (revue), porteparole du Conseil d'Hygiène de la province de Québec, 35, 3: 364

Journal de Médecine de Québec, Le (revue), fondation, 34, 2: 234

Journal des Jésuites, guerre iroquoise, Nouvelle-France, $36,1: 32$ ss

Journaux, voir Presse

Journaux de l'Assemblée Législative (Appendices), inventaire, 31, 4: 563-574

Journeyman Shoemakers' Society, Montréal, 31, 2: 199

Juifs, opposition des Jeune-Canada, 40, 1: 11, 12,15

Jumelage de dossiers, Saguenay-Lac SaintJean, 32, 1: 50 ss

Justice, procès politiques canadiens, $34,1: 57$ 93; répression du crime, Bas-Canada, 38, 4: 499-521

\section{$\mathbf{K}$}

KALM, Pehr (voyageur), vie matérielle, Nouvelle-France, 40, 3: 346, 362, 364

Kamouraska (comté), René Chaloult, 39, 1: 28-33

KASHTAN, William (secrétaire-général du Parti communiste canadien), histoire officielle du Parti communiste canadien, 37, 2: 310

Kaskasia (village), Illinois français, 39, 4: 585, 586, 590

KEALEY, Greg (historien), syndicalisme au Canada, 37, 2: 172 ss

Keewatin (district), annexion au Manitoba, opposition des conservateurs-nationalistes, 35, 1: 39-43

KEMPT, James (gouverneur du Canada), appui à la Literary and Historical Society of Quebec, 35, 2: 180, 181

KING, William Lyon Mackenzie (premier ministre du Canada), commissariat canadien à Paris, 34, 3: 370-375; programme d'allocations familiales, 40, 1: $76 \mathrm{ss}$

KIROUAK, Conrad, voir MARIE-VICTORIN (frère)

Kokotché, croyances algonquiennes, 35, 3 : 377-381

I

LA BRIMANIĖRE, Vincent de (armateur de navires pour Terre-Neuve), 40, 2: 202, 203, 207

LA HOUSSAYE, (armateur de navires pour Terre-Neuve), 40, 2: 197 ss

La Rochelle (France), contrats de pêche, TerreNeuve, 39, 4: 529 ss; commerce France/ Nouvelle-France, 36, 3: 422, 423

LA VALLIĖRE, Alexandre (seigneur de Beaubassin), 37, 3: $405 \mathrm{ss}$

LABELLE, Antoine (curé de Saint-Jérôme), colonisation et émigration dans l'Ouest canadien, 33, 2: 167, 168

Labourage, seigneurie de Saint-Hyacinthe, 40 , 3: 386 
Labrador, pêcheries, Inuit, Nouvelle-France, 31, 4: 481-499

Lac Saint-Jean, voir Saguenay-Lac Saint-Jean

LACHAPELLE, Emmanuel-Persillier (médecin), organisation de la profession et promotion de l'hygiène publique, $35,3: 359$ ss

Lachute, grève du textile à la Cie Ayers, 37, 2: 271-289

Lacolle, seigneurie, gestion des Christie, Richelieu (vallée), 40, 4: 563 ss

LACROIX, Édouard (industriel), Bloc populaire canadien, 39, 1: 38-44

LAFLĖCHE, Louis-François (évêque de TroisRivières), division du clergé, 33, 4: 503 ss

Laïcisation, personnel enseignant, France, 36, 3: $392-397$

Lait, pasteurisation du, Montréal, 36, 4: 522, 523

LALLEMAND, Hierosme (jésuite), tremblement de terre, Nouvelle-France, 36, 3: 375 ss

LAMAISON, Pierre (ethnologue), histoire de la famille, Europe, 39, 2: 174

LAMBERT, John (voyageur), particularismes de la langue française au Canada, 35, 3: 338

LAMENNAIS, Félicité (écrivain), influence sur Joseph-Sabin Raymond, 32, 4: 587 ss

LANDRY, Yves (démographe), démographie différentielle, 38, 3: 359, 360; mariages, Nouvelle-France, 39, 2: 212 ss

LANGEVIN, Adélard (archevêque de SaintBoniface), écoles du Manitoba, 33, 1: 9 ss

LANGLOIS, Godfroy (vice-président de la Ligue de l'Enseignement), 36, 3: 343 ss

Langue française, attitudes après l'Acte d'Union, 34, 2: 257-267; lien avec le catholicisme dans les villes canadiennes, 33, 2: 263-265

Langue québécoise, manuel de l'abbé Thomas Maguire, 35, 3: 337-354

LANOUILLIER DE BOISCLERC, Nicolas (commis des trésoriers généraux de la Marine à Québec), Nouvelle-France, 32, 2: 181-202

Lanterne canadienne, La (journal), réception par la presse canadienne-française, 34,2 : 269-274

LAROCQUE, Charles (évêque de Saint-Hyacinthe), endettement de l'évêché, 33, 4: 557-574

LAROCQUE, François-Antoine (marchand), L'Assomption (village), 39, 3: 329 ss

LASLETT, Peter (démographe), histoire de la famille, Europe, 39, 2: 165 ss, 187
LAURENDEAU, André (journaliste), agnosticisme, 38, 1: 74-78; membre des JeuneCanada: $40,1: 6$ ss

LAURENDEAU, Arthur (musicien, père d'André), 38, 1: 78-81

Laurentide Pulp and Paper Limited, Mauricie, $38,2: 187-189 ; 40,1: 41,42$

LAURIER, Wilfrid (premier ministre du Canada), commissariat canadien à Paris, 34, 3: 360-367; rapatriement et colonisation, 38, 3: 382 ss

Laurier-Greenway, accord, écoles du Manitoba, 33, 1: 5, 10, 11

LAURIN, Joseph (notaire), secrétaire de la Société amicale et bienveillante des charpentiers de vaisseaux de Québec, 37, 2: 243, 235

LAVAL, François de Montmorency (évêque de Québec), confréries, Nouvelle-France, 39, 4: 496 ss; rencontre avec Jean-Baptiste Colbert, 37, 3: 438, 439

Lavaltrie, seigneurie, Barthélémy Joliette, 36 , 2: 178,179

LAVERGNE, Armand (homme politique), membre des conservateurs-nationalistes, 35 , 1: 35 ss

LAW, John (ministre français des Finances), établissement des Allemands en Louisiane, 33, 1: 53 ss

LE BONHOMME DE LA FONTAINE (veuve, armateur de navires pour Terre-Neuve), 40, 2: 202, 204

LE PLAY, Frédéric (sociologue), influence sur Edmé Rameau de Saint-Père, 33, 3: 335 ss

LE ROY LADURIE, Emmanuel (historien), École des Annales, 33, 3: 396-398

LEBEL, Léon (jésuite), allocations familiales, Canada, 40, 1: 77, 80, 89, 90

LEFEBVRE, Jean (négociant), NouvelleFrance, 31, 2: 172 ss

LÉGARÉ, Jacques (démographe), mariages, Nouvelle-France, 39, 2: 212 ss

LÉGARÉ, Joseph (peintre), projet de musée national, 31, 1: 75-82

Législation, éducation, Québec (province), 40 , 4: $517 \mathrm{ss;}$ industrie minière, Québec (province), 37, 4: 592-601; travail: 31, 2: 215 221; travail des enfants et instruction obligatoire, Québec (province), 38, 1: 42-46; voir aussi Droit

LÉPINE, Alphonse Télesphore (député fédéral), écoles du soir, Montréal, 34, 4: 603 ss 
LEROUX, Germain (marchand), L'Assomption (village), 39, 3: 327 ss

LEROY-BEAULIEU, Paul (économiste), système colonial européen, $36,1: 56,69,70$

LÉVESQUE, René (journaliste), émissions d'affaires publiques à la télévision de RadioCanada, 36, 2: 215 ss

Libéralisme, analyse des éditoriaux de $\mathrm{La}$ Presse, 33, 3: 451-462; éducation, Québec (province), 40, 4: 505-535; et libéraux, condamnation par le clergé québécois, 33 , 4: 504-508; Joseph-Édouard Turcotte, 38, 1: 63-68

Libéraux radicaux, réforme de l'éducation, Québec (province), 36, 3: 339-373

Liberté d'expression, émissions d'affaires publiques à la télévision de Radio-Canada, 36, 2: 228-237

Liberté de presse, 31, 4: 501-523

Libertinage, voir Conceptions prénuptiales ou illégitimes; Naissances illégitimes

Librairie, diffusion de la littérature au Québec, $38,4: 537,538$

Ligue de l'Enseignement, réforme de l'éducation, 36, 3: 339-373

Ligue de l'unité ouvrière, section canadienne de l'Internationale ouvrière, $34,2: 174$ ss

Ligue française de l'Enseignement, 36, 3: 344

Ligue pour la défense du Canada, 39, 1: 38

Linguistique québécoise, manuel de l'abbé Thomas Maguire, 35, 3: 337-354

LINTEAU, Paul-André (historien), historiographie de la Revue d' histoire de l'Amérique française, 36, 4: $553 \mathrm{ss}$; propriété foncière, Bas-Canada, 39, 4: 556, 557

Literary and Historical Society of Quebec, 35, 2: $179-192$

Littérature francophone du Québec, historiographie, 38, 4: 523-547; abbé Joseph-Sabin Raymond, 32, 4: 585-602

Livre de comptes, étude des marchands, 38,2 : 212,213

Lods et ventes, seigneuries Christie, Richelieu (vallée), 40, 4: 571, 572

Logement, insalubrité et mortalité, Montréal, $36,4: 519,520$; politique ouvrière, Montréal, 37, 2: 190 ss

Long-Sault, bataille du, motivations des tribus amérindiennes, Nouvelle-France, 35, 2: 163-178

Lotbinière (comté), René Chaloult, 39, 1: 3445
Lotbinlère, seigneurie, peuplement, NouvelleFrance, 39, 3: 392 ss

Lotissement, quartier Saint-Roch, Québec, 34, 4: $569-596$

Louisbourg, forteresse de, Nouvelle-France, 37, 3: 409

Louisiane, commerce avec l'Illinois français, 39, 4: 585, 586; établissement des Allemands, 33, 1: 51-65; immigration, 39, 2: 215; mission de Dominique-Marie Varlet, 36, 2: 198-204; voir aussi Nouvelle-Orléans

Louvre (musée), description dans les récits de voyage sur Paris, 38, 4: 556

LOWER, Arthur Reginald Marsden (historien), système agro-forestier, 33, 1: 73 ss

Loyalistes, installation dans les seigneuries Christie, Richelieu (vallée), 40, 4: 565, 567, 569

$\mathbf{M}$

MACDONALD, John Alexander (premier ministre du Canada), commissariat canadien à Paris, 34, 3: 358-360

Machault, Le (navire français), cargaison pour la Nouvelle-France, 36, 3: 413 ss

MACKENZIE, William Lyon (homme politique), responsabilité ministérielle, 33,1 : 27 ss

Maçons, Québec (ville), 31, 4: 553-559

Madagascar, Jean-Baptiste Colbert, 37, 3: 441, 448, 449

MAGUIRE, Thomas (prêtre), manuel sur la langue québécoise au 19e siècle, $35,3: 337$ 354

MAHIET, Michel (marchand), associé de Joseph Cadet à Mont-Louis, Nouvelle-France, 37, 4: 560 ss

Main-d'oeuvre agricole, seigneurie de SaintHyacinthe, 40, 3: 387

Maison en bois, artisans, Québec (ville) et Montréal, Nouvelle-France, 40, 3: 346-350

Maison en pierre, artisans, Québec (ville) et Montréal, Nouvelle-France, 40, 3: 346-352

Maisons, construction de, Québec (ville), 31, 4: $547-561$

Maisons de correction, Bas-Canada, 38, 4: 518,519 
Malacologie, abbé Léon Provancher, 34, 4: 545 ss

Maladie mentale, voir Asile psychiatrique

Maladies contagieuses, mortalité, Montréal, 36, 4: 519

Maladies vénériennes, discours médical, 38 , 1: $33-37$

MALRAUX, André (écrivain), 37, 4: 536, 540, 541

Manchester, histoire de la famille, États-Unis, 39, 2: 191-193, 204

Manitoba, crise scolaire, 33, 1: 3-23; immigration des Canadiens français, 33, 2: 163-185

Manufactures, travail des enfants, Québec (province), 38, 1: 52, 53; voir aussi Industrialisation; Industries et Manufactures

MARCHAND, Félix-Gabriel (premier ministre du Québec), ministère de l'Instruction publique, 36, 3: 341, 342

MARCHAND, Jean (dirigeant syndical), mutations de la Confédération des travailleurs catholiques du Canada, 34, 3: 378

Marchands, comportement démographique, Montréal, 33, 3: 427-445; critique des sources, 38, 2: 203-222; voir aussi Commerce de détail

Marchand-bourgeois anglais, image-type, Bas-Canada, 39, 4: 553, 554

Marchands britanniques, attitudes envers le régime seigneurial, $35,1: 77 \mathrm{ss} ; 36,2: 166-$ 173; droit de la faillite, Bas-Canada, 40, 2: 217 ss

Marchands généraux, Canada, 33, 4: 521-556

Marchands ruraux, L'Assomption (village), 39, 3: 323-343; Varennes (village), 33, 2: 215-262

Marchands-équipeurs, sociétés de commerce des fourrures, Nouvelle-France, 40, 3: 426428

Marchands-négociants, commerce et crédit, Québec (ville), 36, 4: 527-551

Marchands-voyageurs, sociétés de commerce des fourrures, Nouvelle-France, 40, 3: 421428

Marché, agriculture, basse vallée du Richelieu, 39, 3: 408 ss; économie paysanne, 40, 3: 381-383; vente du blé à Montréal, régime seigneurial, $36,2: 244-252$

Mariage à la gaumine, Nouvelle-France, 40, 2: 269,270

Mariage, âge au, conceptions prénuptiales, Nouvelle-France, 40, 2: 258-264
Mariage, promesses rompues de, abandon d'enfants, Québec (province), 40, 4: 541, 542,558

Mariages, marchands de Montréal, 33, 3: 431 ss; mères et pères d'enfants illégitimes, 40, 2: 249, 250, 258-264; Nouvelle-France, 31, 1: 54-64; Nouvelle-France, NouvelleOrléans, Saint-Domingue, 39, 2: 211-231; solidarités communautaires, $40,1: 62,63$; travailleurs, Sainte-Brigide (paroisse), 39, 2: 233-251; ville et campagne, NouvelleFrance, 38, 3: 365-368

Mariages exogames, gouvernement de Québec, Nouvelle-France, 35, 1: 3-32

MARIE DE L'INCARNATION (religieuse), guerre iroquoise, Nouvelle-France, 36, 1: 33 ss; tremblement de terre, NouvelleFrance, 36, 3: 376 ss

MARIE-VICTORIN (frère), 39, 1, 77-82; utilisation idéologique de son personnage scientifique, 35, 2: 206

Marine de guerre, débat entre les partis politiques, Canada, 35, 1: 33 ss; liens avec la marine civile, France, 36, 3: 324, 325

Marine, ministère de la, administration, France, 32, 2: 181-202; approvisionnement de la Nouvelle-France, 36, 3: 416-418

Marine, troupes de la, mode de paiement, Nouvelle-France, 32, 2: 191 ss

Marseille/Terre-Neuve, commerce de la morue, 40, 2: 193-214

Marsh, rapport (1943), allocations familiales, Canada, 40, 1: 76, 77, 89

Marsouin, pêche au, Rivière-Ouelle, NouvelleFrance, 37, 4: 543-555

MARTINEAU, Paul-G. (échevin de Montréal), réforme de l'éducation, 36, 3: 345

MARX, Karl (économiste), expropriation de la paysannerie, Angleterre, 39, 3: 375, 376

Marxisme, hiérarchie de la paysannerie, 40, 3: 375,376 ; théorie de la famille, 34,2 : $198 \mathrm{ss}$; pertinence pour l'histoire des partis communistes, 37, 2: 316, 317

Masculinité, taux de, Nouvelle-France, Nouvelle-Orléans, Saint-Domingue, 39, 2: 211231

MASĖRES, Francis (procureur général), droit de la faillite, Bas-Canada, 40, 2: 217-221

Massachusetts (paroisse de Sainte Anne de Fall-River), lieux d'origine des Franco-Américains, 38, 3: $415 \mathrm{ss}$

MASSICOTTE, Édouard-Zotique (généalogiste), naissances illégitimes, Nouvelle- 
France, 40, 2: 240; répertoire des contrats d'engagement, Nouvelle-France, 34, 1: 4, 5

Maternité, discours féministe, Québec (province), 37, 1: 86; discours médical, 38, 1: 26-33

Mauricie, agriculture, 35, 4: 537-562; industrialisation, 37, 1: 3-19; 40, 1: 29-50; patronat des entreprises, 38, 2: 181-201

MAZARIN, Jules (cardinal), France, 37, 3: 432, 433

McBEATH, George (marchand), L'Assomption (village), 39, 3: 327, 331

McGill University, école de médecine, 37, 1: $58,59,61$

McGINNIS, William (agent seigneurial), gestion des seigneuries Christie, Richelieu (vallée), 40, 4: 564 ss

McKEAN, Fergus (membre du Parti communiste canadien), Parti communiste canadien, 37, 2: 314

MCLANE, David (espion français), procès, 34, 1: $59 \mathrm{ss}$

MCNAUGHT, Kenneth (historien), procès politiques canadiens, $34,1: 57-93$

Médecine, mouvement réformiste, 34, 2: 223244; normalisation des études, 37, 1: 51-65; organisation de la profession, $35,3: 355-375$

Médecins, vision de la femme, 38, 1: 23-37

Media, émissions d'affaires publiques à la télévision de Radio-Canada, 36, 2: 213-239

MEDICK, Hans (démographe), histoire de la famille, Europe, 39, 2: 172

MEILLEUR, Jean-Baptiste (surintendant de l'éducation), libéralisme, Québec (province), 40, 4: 512-529

Ménages, structure des, histoire de la famille, États-Unis, 39, 2: 187-190

Mentalité religieuse populaire, Québec (province), 35, 2: 263-267

Mentalités, gouvernement de Québec, Nouvelle-France, 32, 1: 57-94; histoire de la famille, Europe, 39, 2: 164-168; NouvelleFrance, 31, 2: 229-238

Menuisiers, Québec (ville), 31, 4: 552-559

Mercantilisme, voir Economie marchande

MERCIER, Honoré (premier ministre du Québec), écoles du soir, 34, 4: 597 ss; législation minière, 37, 4: 595

Mères, versement des allocations familiales, Canada, 40, 1: 92, 93

Méso-analyse, problématique pour le $19 \mathrm{e}$ siècle canadien, 33, 3: 419-425; socio-économie du Québec, 35, 4: 483-521
Messianisme, Franco-Américains, 34, 4: $557-$ 567

METCALFE, Thomas Llewellyn (juge), procès, grève générale de Winnipeg, 34, 1: 70-74

Méthodes quantitatives, utilisation en histoire sociale, 32, 1: 41-56

Micmacs (tribu amérindienne), région de Moncton, 37, 3: 402, 403

Migrations, voir Mobilité géographique

Militaires, conceptions prénuptiales, NouvelleFrance, 40, 2: 267, 271; naissances illégitimes, Nouvelle-France, 40, 2: 250; voir aussi Officiers; Soldats

Militantisme syndical, Confédération des travailleurs catholiques du Canada, 34, 3: 391 ss; travailleurs, Québec (province) et Ontario, 37, 2: 204-222

Mines, industrie de l'amiante, 33, 2: 187-195; Québec (province), 37, 4: 573-602

Ministère de l'Instruction publique, FélixGabriel Marchand, 36, 3: 341, 342

Ministère de la Marine, administration, France, 32, 2: 181-202; approvisionnement de la Nouvelle-France, 36, 3: 416-418

Ministère du Travail, critique des sources statistiques, 37, 2: 222-225

MINVILLE, Esdras (économiste), allocations familiales, Canada, 40, 1: 78; enquête en Gaspésie, 36, 4: 500; système agro-forestier, 33, 1: 69 ss

Missions Étrangères, prêtres des, conflit avec les Jésuites en Louisiane, 36, 2: 202-204

Mobilier, artisans, Québec (ville) et Montréal, Nouvelle-France, 40, 3: 365-370

Mobilité géographique, élites, Saguenay-Lac Saint-Jean, 39, 1: 9, 14, 16; mariages exogames, Nouvelle-France, 35, 1: 7 ss; peuplement, Nouvelle-France, 37, 3: 423 ss; 39, 3: 396, 397; population de Montréal, 35, 4: 523 ss; rôle de la parenté, États-Unis, 39 , 2: 191-193; Saguenay-Lac Saint-Jean, 31, 1: 17, 18; seigneurie de Batiscan, NouvelleFrance, 40, 2: 183-190; solidarités communautaires, 40, 1: $59 \mathrm{ss;}$ travailleurs, SainteBrigide (paroisse), 39, 2: 236-239

Mobilité professionnelle, travailleurs de l'Alcan, Saguenay, 37, 2: 300-304

Mobilité sociale, Saguenay-Lac Saint-Jean, 31, 1: 19

Mobilité socio-professionnelle, élites, Saguenay-Lac Saint-Jean, 39, 1: 9-15 
MOLLER, Herbert (historien-démographe), mariages, Amérique coloniale, 39, 2: 211, 222

Moncton (région), Nouvelle-France, 37, 3 : 399-416

MONDELET, Charles (juge), langue française, Canada-Uni, 34, 2: 261

Monetary Times (journal), commerce de détail canadien, 33, 4: 523 ss

MONIĖRE, Denis (politicologue), hiérarchie de la paysannerie, $40,3: 375$

MONK, Frédérick Debartzch (député de Jacques-Cartier), chef des conservateursnationalistes, $35,1: 33 \mathrm{ss}$

Monnaie, Nouvelle-France, 39, 2: 255, 256

Monopolisation foncière, voir Spéculation foncière

Mont-Louis, seigneurie, pêche de Joseph Cadet, 37, 4: 560 ss

Montmorency, moulins Hall, investissemnents de Timothy Hibbard Dunn, 35, 3: 330

MONTPETIT, Édouard (économiste), commission sur les allocations familiales (19301933), 40, 1: 77, 78; système d'éducation, 36, 1: 3-29

Montréal, alimentation de la population, 36,4 : 521, 522; artisans, Nouvelle-France, 40, 3 : 339-372; démographie, 33, 3: 427-445; 35 , 4: 523-535; 40, 4: 551-556; élection partielle de 1832, 32, 4: 565-584; enfants abandonnés, 40, 4: 537-559; grève des charretiers, 31, 3: 371-395; hygiène publique, 36 , 4: 507-526; industrie de la chaussure, 31,2 : 187-210; marchands, 33, 3: 427-445; politique municipale, 37, 2: 185-199; politique ouvrière, 37, 2: 185-199; réseau d'approvisionnement en blé, régime seigneurial, 36 , 2: 241-262; salles d'asile, 34, 1: 27-55; travailleurs, 33, 1: 39-50; urbanisation, 37, 2: 185-199; 40, 4: 538-558; voir aussi NotreDame de Montréal (paroisse); Sainte-Brigide (paroisse); Saint-Henri (quartier); SaintJoseph (quartier)

Montréal (district), origine du clergé, 37, 3 : 377-380

Montréal, gouvernement de, âge au baptême, Nouvelle-France, 38, 3: 346, 347; conceptions prénuptiales, Nouvelle-France, 40,2 : 264, 265

Montreal Lunatic Asylum, 39, 3: 345-367

Montreal Mechanics' Institute, école du soir, 34, 4: 598 ss
Montreal Medical Institution, voir McGill Université: école de médecine

MOREAU, Louis-Zéphirin (secrétaire de Mgr Charles LaRocque), 33, 4: 561 ss

MORGENTALER, Henry (médecin), comité de défense, $37,1: 83,84$

Mort, attitudes devant la, gouvernement de Québec, Nouvelle-France, 32, 1: 57-94

Mortalité, guerre iroquoise, Nouvelle-France, 36, 1: 31-54; Hôtel-Dieu de Québec, Nouvelle-France, 31, 1: 42-44; Montréal, 36, 4: 507-526; parents des travailleurs, SainteBrigide (paroisse), 39, 2: 244

Mortalité infantile, Conseil d'Hygiène de la province de Québec, 35, 3: 368-370; Crèche d'Youville, Montréal, 40, 4: 549, 550; Montréal, 36, 4: 511-514; naissances illégitimes, Nouvelle-France, 40, 2: 246, 247; prévention, 38, 1:26, 27; ville et campagne, Nouvelle-France, 38, 3: 374-378

Morue, commerce de la, France, 39, 4: 543, 544; France/Antilles/Nouvelle-France, 37, 4: 558, 559; Terre-Neuve/France, 36, 3: 323-338; Terre-Neuve/Marseille, 40, 2: 193214

Morue, pêche à la, Gaspésie, 36, 4: 490 ss; Joseph Cadet, Nouvelle-France, 37, 4: 557572; Labrador, Nouvelle-France, 31, 4: 493499; 39, 4: 533-535

Moulins banaux, seigneuries Christie, Richelieu (vallée), 40, 4: 581; Séminaire de SaintSulpice, 36, 2: 252-256

Mouture, droit de, régime seigneurial, 36, 2: 253

Mouvement des quarante-quatre heures, grèves, imprimerie, 37, 2: 242-251

Mouvement ouvrier, voir Syndicalisme

MURE, John (marchand), lotissement du quartier Saint-Roch, Québec, 34, 4: 584 ss

Musée Chasseur (musée d'histoire naturelle de Québec), 31, 1, 75, 76

Musée d'histoire naturelle, 35, 2: $190 \mathrm{ss;} \mathrm{Lit-}$ erary and Historical Society of Quebec, 31, $1: 75,76$

Musée de l'Université Laval, 31, 1: 82

Musée du Séminaire de Québec, 31, 1: 82

Musée national, projet de, Québec (ville), 31 , 1: $75-82$ 
NICOLLET, Jean (explorateur), voyage au lac Supérieur, Nouvelle-France, 34, 2: 183-196

Naissances, marchands de Montréal, 33, 3: 434 ss; Nouvelle-France, 31, 1: 59-64; ville et campagne, Nouvelle-France, 38, 3: 368374; voir aussi Baptêmes; Conceptions illégitimes ou prénuptiales; Naissances illégitimes

Naissances illégitimes, Nouvelle-France, 40 , 2: 239-252; travailleurs, Sainte-Brigide (paroisse), 39, 2: 243, 244; voir aussi Conceptions illégitimes ou prénuptiales

Napierville (village), rentes seigneuriales, 40, 4: 571

Natalité, allocations familiales, Canada, 40, 1: 88-91

National Research Council of Canada, voir Conseil national de recherches du Canada

Nationalisme, René Chaloult, 39, 1: 25-50; Guy Frégault, 36, 4: 569-582; Lionel Groulx, 36, 4: 569-582; Jeune-Canada, 40, 1: $5 \mathrm{ss}$; littérature francophone du Québec, 38, 4: 530-532; Maurice Séguin, 38, 4: $578 \mathrm{ss}$

'Nationalisme et catholicisme, Lionel Groulx, 32, 3: 378-383

Nationalisme et syndicalisme québécois, 35 , 3: $397-406$

Naturaliste canadien (revue), abbé Léon Provancher, 34, 4: 536 ss

Navigation, Richelieu, 38, 1: 15-20

Navire-marchand, construction navale, vallée du Saint-Laurent, 35, 2: 239 ss

Navires, avitaillement des, financement, TerreNeuve, 39, 4: 540-542

NELSON, Wolfred (médecin), navigation sur le Richelieu, 38, 1: 14-16

Néo-nationalisme, Maurice Séguin, 38, 4: 570 ss

Neuville (paroisse), mariages exogames, Nouvelle-France, $35,1: 4$ ss

New Hampshire (paroisses de Saint-Anthony et Saint-Jean-Baptiste), lieux d'origine des Franco-Américains, 38, 3: 415 ss

New South Wales System, système de distribution foncière, 36, 2: 183, 184

Nicolet (comté), agriculture, 35, 4: 549 ss

Nicolet (diocèse), clergé, 35, 3: 383-395

Nicolet, séminaire de, origine du clergé, 37,3 : 390, 391

Noirs, mariages, Nouvelle-Orléans, Saint-

Domingue, 39, 2: 213-231

Noranda Mines Ltd, 37, 4: 585

Notables, voir Élites

Notre-Dame de Montréal (paroisse), baptêmes légitimes et illégitimes, 40, 4: 552-556

Notre-Dame de Paris (cathédrale), récits de voyage sur Paris, 38, 4: 554

Notre-Dame de Québec (paroisse), alphabétisation, 39, 1: 63-76; inventaire après décès, $34,4: 515-533$

Nouveau-Québec, législation minière, 37, 4: 597-599

Nouvelle-Angleterre, établissement de congrégations françaises, 36, 3: 405; immigration des Canadiens français, 34, 4: 557-567

Nouvelle-Écosse, Acadiens, Nouvelle-France, 37, 3: 409-410

Nouvelle-France, civilisation de la, oeuvre de Guy Frégault, 35, 1: 60 ss

Nouvelle-Orléans, comportements matrimoniaux, 39, 2: 211-231

Noyan, seigneurie, gestion des Christie, Richelieu (vallée), 40, 4: 563 ss

Numéraire, fortune des artisans, Québec (ville) et Montréal, Nouvelle-France, 40, 3: 354, 355

Nuptialité, voir Mariages

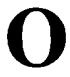

Obligation, étude des marchands, 38, 2: 216, 217

Obligation scolaire, voir Instruction obligatoire O'CALLAGHAN, Edmund Bailey (rédacteur du Vindicator), responsabilité ministérielle, $33,1: 30$

Oeuvre des Tracts, collection de brochures de l'École sociale populaire, 35, 4: 572

Ofticiers, sociétés de commerce des fourrures, Nouvelle-France, 40, 3: 418-428

O'LEARY, Dostaler (membre des JeuneCanada), 40, 1, 22-26

Oligopole, industrie minière, Québec (province), $37,4: 581$ ss 
Onontagués (tribu amérindienne), mission française à Sainte-Marie de Gannentaha, Nouvelle-France, 35, 2: 174-175

Ontario, syndicalisation et grèves, 37,2 : 209 ss; travail des enfants et fréquentation scolaire, 38, 1: 47-51

Ontario, Nord de l', émigration des Canadiens français, 33, 2: 174 ss

Opérations Dignité, Bas Saint-Laurent, 35, 2 : 255-257

Or, industrie minière, Québec (province), 37 , 4: 574,575

Orangistes, violence, Québec (province), 37, 1: $75-77$

Ordinations, clergé canadien-français, 37,3 : 375-377

Ordre de Jacques-Cartier, 40, 2: 284, 285 , 287

Ordre, L' (journal), répliques à La Lanterne canadienne, 34, 2: 269 ss

Ordre nouveau, L' (journal), École sociale populaire, $32,2: 211,212 ; 35,4: 577-580$

Organisation du territoire et culture, Nouvelle-France, 37, 3: 417-429

Organisation du travail, Montréal, 33, 1 : 39 50

OUELLET, Fernand (historien), attitudes des marchands britanniques envers le régime seigneurial, 35, 1: 77; Conquête et Rébellions de 1837-1838, 38, 2: 228, 236, 237; engagements dans le commerce des fourrures, Nouvelle-France, 34, 1: 3, 4; hiérarchie de la paysannerie, $40,3: 376,377$; influence de l'École des Annales, 33, 3: 375

Ouest canadien, établissement de congrégations françaises, 36, 3: 405; immigration des Canadiens français, 33, 2: 163-185; rapatriement et colonisation, 38, 3: 395 ss

Ouinipigous (Amérindiens des Grands Lacs), ambassade de Jean Nicollet, NouvelleFrance, 34, 2: 183-196

Outillage agricole, hiérarchie de la paysannerie, seigneurie de Saint-Hyacinthe, 40, 3: 396,397

Ouvriers, voir Travailleurs

\section{$\mathbf{P}$}

Pacotille, transport de marchandises personnelles sur les bâtiments de commerce, 36,3 : 419-421

Pain, prix et poids, régime seigneurial, 36,2 : 247-250

PAPILLON, Antonin, (historien), 37, 4: 535

PAPINEAU, Louis-Joseph (homme politique), libéralisme et démocratie, 38, 1: 65, 66; portrait par Fernand Ouellet, 34, 3: 429 ss; responsabilité ministérielle, $33,1: 29$ ss

PAQUET, Gilles (économiste), crise agricole, 38, 2: 231-233; hiérarchie de la paysannerie, 40, 3: 377, 378; histoire du bas-Canada, $34,3: 416 \mathrm{ss}$; inventaires après décès, 34,4 : $515 \mathrm{ss}$

PAQUETTE, Albini (médecin et député), suffrage féminin, 38, 1: 33

PARENT, Étienne (journaliste), grève des charpentiers de navires, Québec (ville), 37, 2: 237; langue française, Canada-Uni, 34, 2 : 259 ss

PARENT, Madeleine (syndicaliste), grève du textile, Lachute, 37, 2: 271 ss

Parenté, histoire de la famille, États-Unis, 39 , 2: 187-193; histoire de la famille, Europe, 39, 2: $172 \mathrm{ss}$; 5; influence sur l'exogamie, Nouvelle-France, 35, 1: 22 ss; mobilité géographique, 40, 1: 59, 60, 66-68; peuplement, Nouvelle-France, 39, 3: 400-404; travailleurs, Sainte-Brigide (paroisse), 39, 2: 245

Parents québécois, perception des allocations familiales, 40, 1: 80-84, 92

Paris, récits de voyage, $38,4: 549-568$

PARKHURST, Anthony (navigateur), nombre de navires à Terre-Neuve, 39, 4: 529, 530

Parti britannique, élection partielle de 1832 , Montréal, 32, 4: 567 ss

Parti bureaucrate, voir Parti britannique

Parti communiste canadien, 34, 2: 173-175; historiographie, 37, 2: 309-319

Parti conservateur, Jeune-Canada, 40, 1: 14, 15

Parti libéral, René Chaloult, 39, $1: 28$ ss; opposition des Jeune-Canada, 40, 1: 12-17

Parti national, René Chaloult, 39, 1: 30-34

Parti ouvrier de Montréal, 37, 2: 189 ss

Parti ouvrier-progressiste, voir Parti communiste canadien 
Parti patriote, voir Patriotes

Parti québécois, avortement, 37, 1: 84, 85

Parti réformiste (Canada-Uni), libéralisme, 40, 4: 509, 511

Pasteurisation du lait, Montréal, 36, 4: 522, 523

Pâtes et papier, Consolidated Paper Limited, Mauricie, 40, 1: $35 \mathrm{ss;}$ industrialisation, Mauricie, 37, 1: 9 ss

Paton, fabrique de lainage, Sherbrooke, 38, 2: 169 ss

Patrie, La (journal), réforme de l'éducation, 36 , 3: 347 ss

Patrimoine foncier, Québec (région), 39, 4: 566-576

Patrimoine, transmission du, 39, 4: 557, 558; histoire de la famille, Europe, 39, 2: 170, 174, 175; solidarités communautaires, 40 , 1: 62 ; voir aussi Terres, mode de transmission

Patriotes, activités de Joseph-Édouard Turcotte, 38, 1: 59-71; droit de la faillite, BasCanada, 40, 2: $226 \mathrm{ss}$; procès devant la Cour martiale, $34,1: 59$ ss; responsabilité ministérielle, 33, 1: 25-37

Patronat des entreprises, Mauricie, 38, 2: 181-201

Paysannerie, hiérarchie, seigneurie de SaintHyacinthe, 40, 3: 373-407; expropriation, Angleterre, 39, 3: 375-379

Pêche à la morue, voir Morue, pêche à la

Pêche au marsouin, voir Marsouin, pêche au

Pêcheries, Gaspé, 36, 4: 485 ss; 37, 4: 565569; Labrador, Nouvelle-France, 31, 4: 481-499; Terre-Neuve, 39, 4: 523-549

Pêcheurs basques, modalités d'engagement, Nouvelle-France, 37, 4: 558 ss; TerreNeuve, 39, 4: 532 ss

Pédagogie, écoles primaires, Ligue de l'Enseignement, 36, 3: $355 \mathrm{ss}$

PEIGNÉ, Eugène-Marie (investisseur français dans la Compagnie de Colonisation et de Crédit des Cantons de l'Est), 32, 1: 22 ss

Peines, répression du crime, Bas-Canada, 38, 4: $517-520$

Peinture d'histoire, Charles Huot, 31, 3: 397405

PEIRE, Philippe, (entrepreneur), pêche au marsouin, Nouvelle-France, 37, 4: 547-553

PEIRE, Pierre (entrepreneur), pêche au marsouin, Nouvelle-France, 37, 4: 544-547

Pénélope, La (navire français), transport de pacotille, 36, 3: 420, 421
PENNER, Norman (politicologue), Parti communiste canadien, 37, 2: 312, 313

Pensions (résidence), structure de la famille, États-Unis, 39, 2: 189, 190; travailleurs, Sainte-Brigide (paroisse), 39, 2: 245, 246

PENTLAND, H. Clare (historien), Labour and Capital in Canada 1650-1860, 38, 2: 245253

Perception des rentes seigneuriales, seigneuries Christie, Richelieu (vallée), 40, 4: 572577

PERRAULT, Julien (maître-boulanger), faubourg Saint-Laurent (Montréal), 36, 2: 259

Petitcodiac (région), Acadie, Nouvelle-France, 37, 3: 400 ss

Petite-bourgeoisie, discours éducatif, Québec (province), 32, 2: 159-179

Pétitions, étude de l'alphabétisation, 39, 1: 52

PÉTRIMOULX, Pierre-Médard (marchand), L'Assomption (village), 39, 3: 329, 331

Peuplement, colonisation, Nouvelle-France, 39, 3: 391-405; influence de la guerre iroquoise, 36, 1: 44-46; Nouvelle-France, 39, 2: $255 ; 40,2: 275,279,281$

Phoques, chasse aux, Labrador, NouvelleFrance, 31, 4: 487-493

Phosphate, industrie minière, Québec (province), 37, 4: 574, 575

PILON-LÊ, Lise (anthropologue), capitalisation de la rente seigneuriale, 36, 2: 178. 179

PINEL, Philippe (médecin), traitement de la folie, 39, 3: 347, 348, 359

PINSONEAULT, Alfred (avocat), perception des rentes des seigneuries Christie, Richelieu (vallée), 40, 4: 573, 574, 576

PIVA, Michael (historien), syndicalisme au Canada, 37, 2: 180

Place de la Concorde, récits de voyage sur Paris, 38, 4: 555

PLANTE, Anatole (médecin et député), suffrage féminin, $38,1: 31,32$

Plébiscite, voir Conscription

Poêle, artisans, Québec (ville) et Montréal, Nouvelle-France, 40, 3: 358, 359

Poésie politique, Joseph-Édouard Turcotte, 38, 1: 60-63

POINDRON, Anatole (directeur de l'agence commerciale à Paris), 34, 3: 361

"Point de mire", émission d'affaires publiques à la télévision de Radio-Canada, 36, 2: 215 ss

Poisson, commerce et consommation, France, $39,4: 543-547$ 
Police, aide au pouvoir civil, Québec (province), 37, 1: 67-79

Politique municipale, Montréal, 37, 2: 185199

Politique ouvrière, Montréal, 37, 2: 185-199

Pologne, syndicalisme, 35, 3: 405, 406

POMROY, Benjamin (homme d'affaires), Banque des Cantons de l'Est, 38, 2: 167169

PONCET, Joseph-Antoine (jésuite), fondation de confréries, Nouvelle-France, 39, 4: 496, 497

Population, voir Démographie

Port de Québec, construction navale, 35, 2: 231-251

POTIER, Pierre-Philippe (jésuite), particularismes de la langue française au Canada, 35 , 3: 337,338

POULIN, Ernest (médecin et député), suffrage féminin, 38, 1: 32

POZER, George (marchand), rentes du quartier Saint-Roch, Québec, 34, 4: 587 ss

Pratique de la médecine, diplômes et permis, 37, 1: 60-63; qualités, 38, 1:24, 25

Prénoms, transmission des, Nouvelle-France, 31, 1: $67-70$

Prénuptialité, voir Conceptions illégitimes ou prénuptiales

Presse, Cantons de l'Est, 31, 2: 239-253; diffusion de la littérature au Québec, 38, 4: 534; opinions sur la langue française, Canada-Uni, 34, 2: 257 ss

Presse, liberté de, 31, 4: 501-523

Presse canadienne-française, réception de $\mathrm{La}$ Lanterne canadienne, 34, 2: 269-274

Presse, La (journal), analyse des éditoriaux, 33, 3: $451-462$

Prêts hypothécaires, investissemnents de Timothy Hibbard Dunn, 35, 3: 325 ss

Primeur, commerce de la morue, Terre-Neuve/ Marseille, 40, 2: 198, 201-204

Prisons, Bas-Canada, 38, 4: 518-520

Procès politiques canadiens, insurrection appréhendée, 34, 1: 57-93

Professions, alphabétisation, Québec (ville), 39, 1: 66 ss; associés du commerce des fourrures, Nouvelle-France, 40, 3: 421-428; L'Assomption (village), 39, 3: 325, 326; migrants internes de Montréal, 35, 4: 528531 ; ville et campagne, Nouvelle-France, 38, 3: 363, 364

Professions libérales, Saguenay-Lac SaintJean, 39, 1: 7 ss
Programme catholique, manifeste ultramontain au sujet des élections, 33, 4: 503, 504

Programme d'études, écoles primaires, Ligue de l'Enseignement, 36, 3: 356 ss

Programme d'études en médecine, normalisation, 37, 1: 57-59

Programme de recherche en démographie historique (Université de Montréal), 31, 1: 49; 38, 3: 341-356; 40, 2: 241 , 255, 256; registre de population de la NouvelleFrance, 38, 3: 423-426

Projet d'histoire sociale de la population du Saguenay, 31, 1: 3; méthodologie, 32, 1: 41-56; voir aussi Centre interuniversitaire de recherches sur les populations

Propriété foncière, artisans, Québec (ville) et Montréal, Nouvelle-France, 40, 3: 346-354; François-Augustin Bailly de Messein, Varennes (village), 33, 2: 219 ss; BasCanada, 36, 2: 163-194; hiérarchie de la paysannerie, seigneurie de Saint-Hyacinthe, 40, 3: 387-391; marchands, L'Assomption (village), 39, 3: 340-343; voir aussi Fortune immobilière

Propriété, système de, quartier Saint-Roch, Québec, 34, 4: 575 ss

Prostitution, discours médical, 38, 1: 33-37

Protestantisme, Nouvelle-France, 31, 3: 325 349

PROVANCHER, Léon (abbé), bibliothèque scientifique, 34, 4: 535-556

Psychiatrie, asile, Québec (province), 39, 3: 345-367

Puants (tribu amérindienne), voir Ouinipigous

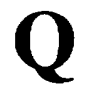

Quadragesimo Anno (encyclique), restauration de l'ordre social, 35, 4: 568-569

Québec (district), origine du clergé, 37, 3 : $377-380$

Québec (vilie), alphabétisation, 39, 1: 63-76; artisans, Nouvelle-France, 40, 3: 339-372; artisans du cuir, 34, 3: 341-356; commerce et crédit, 36, 4: 527-551; construction domiciliaire, 31, 4: 547-567; construction navale, 35, 2: 231-251; 37, 2: 227-239; garnison, Nouvelle-France, 32, 4: 535-563; 
projet de musée national, 31, 1: 75-82; voir aussi Notre-Dame de Québec (paroisse); Saint-Jean (quartier); Saint-Roch (paroisse et quartier)

Québec, gouvernement de (Nouvelle-France), conception prénuptiales, $40,2: 264,265$; confréries, 39, 4: 491-522; mariages exogames, 35, 1: 3-32; mentalités, 32, 1: 57-94

Quebec Journeymen Shoemakers' Society, 31, 2: 196

Québec-Comté, René Chaloult, 39, 1: 45-49

Quebec-Lake St.John Railway, rapatriement et colonisation, 38, 3: 383, 386, 394

QUÉNIART, Jean (historien), étude de l'alphabétisation, 39, 1: 62

Quittance, étude des marchands, 38, 2: 216, 217

$\mathbf{R}$

Racisme, pensée de Edmé Rameau de SaintPère, 36, 1: 61, 62

RADISSON, Pierre-Esprit (explorateur), récits de voyages, Nouvelle-France, 34, 3: 407414

RAMEAU DE SAINT-PĖRE, Edmé (historien), colonisation européenne, 36,1 : 55-74; conception du métier d'historien, 33, 3: 331355

RAMEZAY, Claude de (gouverneur de Montréal), Nouvelle-France, 37, 4: 603-605

RAMEZAY, Jean-Baptiste-Nicolas Roch de (militaire), capitaux, 37, 4: 603-610

Rapatriement des Franco-Américains, Saguenay-Lac Saint-Jean, 38, 3: 379-408

RAUDOT, Jacques (intendant), pêche au marsouin, Nouvelle-France, 37, 4: 544 ss

RAYMOND, Joseph-Sabin (abbé), conception de la littérature, 32, 4: 585-602

RAYMOND, Maxime (homme politique), René Chaloult, 39, 1: 32 ss

Rébellions de 1837-1838, historiographie, 38, 2: 233-242; procès, 34, 1: 59 ss; seigneuries Christie, Richelieu (vallée), 40, 4: 565, 573,574

Recensement canadien de 1941, lien entre langue française et religion catholique dans les villes, 33, 2: 263-265
Recensements, étude de l'alphabétisation, 39, $1: 53,54$

Recensements nominatifs, banques de données, Nouvelle-France, 38, 3: 423-426; Saguenay-Lac Saint-Jean, 32, 1: 44 ss

Recherches scientifiques, indications bibliographiques, 35, 2: 199 ss

Recherches sociographiques, colloque de 1962 à l'Université Laval, influence de l'École des Annales, 33, 3: 368-374

Récit de ce qui s'est passé au voyage que Monsieur de Courcelles Gouverneur de la Nouvelle France a fait au Lac Ontario, ou, des Irocquois, attribution du récit, 32, 2: 239-250

Récits de voyage, Paris, 38, 4: 549-568

Récollets, fondation du Tiers ordre franciscain, Nouvelle-France, 39, 4: 498; NouvelleFrance, 31, 1: 53

Reconstitution des familles, Saguenay-Lac Saint-Jean, 31, 1: 8; 32, 1: 50 ss

Réforme urbaine, Montréal, 37, 2: 185-199

Réformistes (Haut-Canada), responsabilité ministérielle, 33, 1:27 ss

Régime agraire, Saguenay-Lac Saint-Jean, 31, 1: $12-17$

Régime seigneurial, Acadie, Nouvelle-France, 37, 3: 407, 408; Nouvelle-France, 39, 2 : 255; pratiques foncières de la bourgeoisie marchande, Bas-Canada, 36, 2: 166 ss; transition du féodalisme au capitalisme, 35 , 1: $74 \mathrm{ss;}$ voir aussi Seigneuries

Registre d'état civil des mariages, étude de l'alphabétisation, 39, 1: 56-58

Registre de vente des terres par le shérif, étude des marchands, 38, 2: 214, 215

Registres paroissiaux, banques de données, Nouvelle-France, 38, 3: 423-426; Saguenay-Lac Saint-Jean, 32, 1: 43 ss

Réglementation ecclésiastique, âge au baptême, Nouvelle-France, $38,3: 342,345$, 346

REINHART, John (négociant), Québec (ville), 36, 4: 535 ss

Relations, revue, École sociale populaire, 32, $2: 212,213 ; 35,4: 580$

Relations des Jésuites, guerre iroquoise, Nouvelle-France, $36,1: 32$ ss; voyage de Jean Nicollet, Nouvelle-France, 34, 2: 184 ss

Relations France-Canada, 31, 3: 351-370; commissariat canadien à Paris, 34, 3: 357376; échanges culturels, 38, 4: 542, 543 
Religion catholique, comportement devant la mort, gouvernement de Québec, NouvelleFrance, 32, 1: 57-94; lien avec la langue française dans les villes canadiennes, 33, 2: 263-265; Québec (province), 39, 1: 83-89

Remariage, Nouvelle-France, NouvelleOrléans, Saint-Domingue, 39, 2: 221-224, 228

Remboursement du crédit, marchands-négociants, Québec (ville), 36, 4: 547

RÉMY DE COURCELLES, Daniel de (gouverneur de la Nouvelle-France), voyage au Lac Ontario, 32, 2: 239-250

Rentes constituées, quartier Saint-Roch, Québec, 34, 4: 579 ss

Rentes foncières, quartier Saint-Roch, Québec, 34, 4: 579 ss

Rentes seigneuriales, renforcement par les seigneurs, 36, 2: 174-181; taux et perception dans les seigneuries Christie, Richelieu (vallée), 40, 4: 566-577

Répression, criminalité, Bas-Canada, 38, 4: 499-521

Résidence, lieux de, travailleurs, Sainte-Brigide (paroisse), 39, 2: 244, 245

Responsabilité ministérielle, voir Gouvernement responsable

Restauration sociale, programme de l'École sociale populaire, $35,4: 573-575$

Réunion, droit de, seigneurie de Batiscan, Nouvelle-France, 40, 2: 175

Révolution agricole, Angleterre, 39, 3: 377, 378

Révolution américaine, effets au Canada, 39, 3: $386-388$

Révolution anglaise, 39, 3: 385

Révolution démographique, Angleterre, 39, 3: 377,378

Révolution industrielle, Angleterre, 39, 3: 379-386

Révolution tranquille, Guy Frégault, 36, 4: 573,574

Revue d'histoire de l'Amérique française, collaborateurs, 36, 4: 560-563; fonctionnement, 38, 1: 34; 40, 1: 3; historiographie, 1972-1981 , 36, 4: 553-567; présentation du numéro thématique, $32,3: 323 ; 37,2: 163$; 38, 2: $163 ; 38,3: 339$

Rhode Island, lieux d'origine des Franco-Américains, 38, 3: $415 \mathrm{ss}$

Richelieu (vallée), agriculture, 39, 3: 407-413; commerce du blé et navigation, $38,1: 5-21$; défense de la Nouvelle-France, 37, 1: 23 ss; gestion des seigneuries Christie, 40, 4: 561582

Richesse, voir Fortune

RIEL, Louis (chef métis), procès, $34,1: 69,70$; projet de publication intégrale de ses écrits, 33, 3: 447-450

Ristigouche (rivière), fouilles archéologiques, $36,3: 413,414$

RIVERIN, Joseph (entrepreneur), pêche au marsouin, Nouvelle-France, 37, 4: 547, 548

Rivière à Veillette, colonisation, seigneurie de Batiscan, Nouvelle-France, 40, 2: 164 ss

Rivière Champlain, colonisation, seigneurie de Batiscan, Nouvelle-France, 40, 2: 171 ss

Rivière des Envies, colonisation, seigneurie de Batiscan, Nouvelle-France, 40, 2: 166 ss

Rivière-Ouelle, pêche au marsouin, NouvelleFrance, 37, 4: 543-555

Rivière-Ouelle (paroisse), mariages exogames, Nouvelle-France, 35, 1: 4 ss

Rivière-Ouelle, seigneurie, peuplement, Nouvelle-France, 39, 3: 392 ss

ROBERT, Jean-Claude (historien), propriété foncière, Bas-Canada, 39, 4: 556, 557; Rébellions de 1837-1838, 38, 2: 238, 239

ROBIN, Charles (marchand), pêche, Gaspésie, 36, 4: 488-493

Robin, Pipon et Co., pêche, Gaspésie, 36, 4: 488-493

ROBLIN, Rodmond Palen (premier ministre du Manitoba), écoles, 33, 1: 13 ss

RODNEY, William (historien), Parti communiste canadien, 37, 2: 311, 312

ROSA, Narcisse (constructeur de navires), répertoire des navires construits à Québec, $35,2: 234-236$

Rosaire, confrérie du, gouvernement de Québec, Nouvelle-France, 39, 4: 492 ss

ROSE, Fred (organisateur communiste), grève du textile, Cowansville, 34, 2: 171 ss

Rotation des cultures, seigneurie de SaintHyacinthe, 40, 3: 385, 386

Rouen (France), contrats de pêche, TerreNeuve, 39, 4: 529, 531, 533

ROUER D'ARTIGNY, Louis (entrepreneur), pêche au marsouin, Nouvelle-France, 37, 4: 547-550

ROUSSELOT, Victor (sulpicien), fondation de la salle d'asile Saint-Joseph (Montréal), 34, 1: 28 ss

ROUTHIER, Adolphe-Basile (juge), récits de voyage sur Paris, 38, 4: 554 ss 
ROUX, Jean-Baptiste (commerçant de morue), Marseille (France), 40, 2: 196 ss

ROUX, Pierre-Honoré (commerçant de morue), Marseille (France), 40, 2: 196 ss ROWLEY, Kent (syndicaliste), grève du textile, Lachute, 37, 2: 271 ss

ROY, Camille (abbé), querelle autour de $L$ ' $A p$ pel de la race de Lionel Groulx, 32, 3: 399. 405

ROY, Philippe (commissaire canadien à Paris), 34, 3: 363-375

RUMILLY, Robert (historien), 37, 4: 535, 536

RYERSON, Stanley (historien), Rébellions de 1837-1838, 38, 2: 240, 241

\section{Q}

Sabrevois, seigneurie, gestion des Christie, Richelieu (vallée), 40, 4: 563 ss

Sacré-Coeur, basilique du, récits de voyage sur Paris, 38, 4: 555, 556

Sacré-Coeur, confrérie du, gouvernement de Québec, Nouvelle-France, 39, 4: 492 ss

Sacrée Congrégation de la Propagande, guides et inventaires pour l'Amérique du Nord, 33, 2: 197-214; intervention dans l'Église canadienne, 33, 4: 499-519

Saguenay, travailleurs de l'Alcan, 37, 2: 291308

Saguenay-Lac Saint-Jean, 31, 1: 3-27; colonisation et rapatriement, 38, 3: 379-408; démographie, 32, 1: 41-56; élites, 39, 1:323

Saint-Cuthbert (paroisse), émigration aux États-Unis, 38, 3: 417-422

Saint-Denis (paroisse), agriculture, 39, 3: 407413

Saint-Domingue, comportements matrimoniaux, 39, 2: 211-231

Saint-François, district, presse, 31, 2: 239-253

Saint-Henri (quartier, Montréal), salle d'asile, $34,1: 29$ ss

Saint-Hyacinthe, endettement de l'évêché, 33, 4: 557-574; Union internationale des travailleurs en chaussures, $36,1: 89,90$; seigneurie, hiérarchie de la paysannerie, $40,3: 373$ 407
Saint-Jean (quartier, ville de Québec), construction, 31, 4: 550

Saint-Joseph (quartier, Montréal), salle d'asile, 34, 1: 29 ss

Saint-Malo (France), armateurs de navires pour Terre-Neuve, 40, 2: 195 ss

Saint-Maurice (comté), agriculture, 35, 4: 549 ss

Saint-Narcisse (paroisse), seigneurie de Batiscan, Nouvelle-France, 40, 2: 166 ss

Saint-Nicolas (paroisse), mariages exogames, Nouvelle-France, 35, 1:4 ss

Saint-Ours (paroisse), agriculture, 39, 3: 407413

Saint-Roch (paroisse, ville de Québec), alphabétisation, 39, 1: 63-76

Saint-Roch (quartier, ville de Québec), construction, 31, 4: 550-552; rente et lotissement, 34, 4: 569-596

Saint-Stanislas (paroisse), seigneurie de Batiscan, Nouvelle-France, 40, 2: 164, 171, 181

SAINT-VALLIER, Jean-Baptiste de la Croix de Chevrières de (évêque), mission de Louisiane, 36, 2: 198 ss; morale sexuelle, Nouvelle-France, 40, 2: 254, 255, 269

Sainte-Anne, confrérie de, gouvernement de Québec, Nouvelle-France, 39, 4: 492 ss

Sainte-Anne (paroisse), seigneurie de Batiscan, Nouvelle-France, 40, 2: 179 ss

Sainte-Brigide (paroisse), mariages et famille, travailleurs, 39, 2: 233-251

Sainte-Famille, contrérie de la, gouvernement de Québec, Nouvelle-France, 39, 4: 492 ss

Sainte-Geneviève (paroisse), seigneurie de Batiscan, Nouvelle-France, 40, 2: 174 ss

Sainte-Théodosie (paroisse), voir CalixaLavallée (paroisse)

Saisies, droit de la faillite, Bas-Canada, 40, 2: 223, 224

SALÉE, Daniel (politicologue), effets de la Conquête, 39, 3: 369, 370

SALLENAVE, Pierre (littéraire), littérature francophone du Québec, 38, 4: 532, 533

Santé publique, voir Hygiène publique

Satellisation, industrie minière, Québec (province), 37, 4: 582 ss

Savants canadiens, biographie des, indications bibliographiques, 35, 2: 197 ss

SAVARY DES BRÔLONS, Jacques (auteur), définition de la société d'affaires, 40,3 : 412,415 
Scapulaire de Notre-Dame du Mont-Carmel, confrérie du, gouvernement de Québec, Nouvelle-France, 39, 4: 492 ss

SCHEVENELS, Walter (secrétaire-général de la Fédération internationale des syndicats ouvriers), appui au Front populaire espagnol, 33, 4: 576-578

Sciences, bibliothèque de l'abbé Léon Provancher, 34, 4: 535-556

Sciences et techniques au Canada, histoire des, historiographie, 35, 2: 193-215

Sciences naturelles, frère Marie-Victorin, 39, 1: $78,79,81$

Scleries, seigneuries Christie, Richelieu (vallée), 40, 4: 577-581

Scolarité, élites, Saguenay-Lac Saint-Jean, 39, $1: 16,17$

Sectarisme religieux, violence, Québec (province), 37, 1: 75-78

SÉGUIN, Maurice (historien), 37, 4: 534; 38, 4 : 569-590; néo-nationalisme, 38, 2: 226 ss

SÉGUIN, Normand (historien), théorie du peuplement et du développement, SaguenayLac Saint-Jean, 31, 1: 4 ss; système agroforestier, 33, 1: $70 \mathrm{ss}$

SÉGUIN, Robert-Lionel (ethnologue), libertinage, Nouvelle-France, 40, 2: 253, 254

Seigneuries, gestion des seigneuries Christie, Richelieu (vallée), 40, 4: 561-582; organisation du territoire, Nouvelle-France, 37, 3: 419 ss; peuplement, Nouvelle-France, 39, 3: 392-405; voir aussi Régime seigneurial

Sels, voir Gabelle, droits de

Semaines sociales du Canada, oeuvre de l'École sociale populaire, 32, 2: 210 ss

Séminaire de Nicolet, origine du clergé, 37,3 : 390,391

Séminaire de Saint-Sulpice, moulins banaux, $36,2: 252-256$

Sentinelle, La (journal), Franco-Américains, 34, 4: 565 ss

Séparatisme, voir Indépendance (Québec, province)

Sépultures, marchands de Montréal, 33, 3: 443; Nouvelle-France, 31, 1: 59-64; voir aussi Décès

Services, travail des enfants, Québec (province), 38, 1: 52, 53

Services publics, politique ouvrière, Montréal, 37, 2: 190, 191

SÉVIGNY, Albert (député de Dorchester), membre des conservateurs-nationalistes, 35 , 1: 33-54
Sexualité, histoire de la famille, Europe, 39, 2: 166, 167; morale, Nouvelle-France, 40, 2: 254,255

Shawinigan Chemicals, Mauricie, 37, 1: 8 ss; patronat, Mauricie, 38, 2: 195, 196

Shawinigan Cotton, Mauricie, 40, 1: 40

Shawinigan Water and Power, Mauricie, 37, 1: 5 ss; $40,1: 35$ ss; patronat, Mauricie, 38, 2: 187 ss

SHEDDEN, John (entrepreneur en voiturage), grève des charretiers, Montréal, 31, 3: 377394

Sherbrooke Gazette and Townships Advertiser (journal), 31, 2: 250, 251

Sherbrooke (région), construction de chemins de fer, 31, 4: 525-545

Sherbrooke (ville), débentures municipales, Banque des Cantons de l'Est, 38, 2: 168, 169

SHORTER, Edward (historien), famille moderne, 39, 2: 206, 207; histoire de la famille, Europe, 39, 2: 176-179

SIFTON, Clifford (ministre fédéral), Société de rapatriement et de colonisation du Lac SaintJean, 38, 3: 384, 394, 397

Signature, étude de l'alphabétisation, 39,1 : 58-62

SIMARD, Paul (membre des Jeune-Canada), 40, $1: 13$ ss

SIMON, Charles (récollet), tremblement de terre, Nouvelle-France, 36, 3: 376 ss

Skylark (journal), Cantons de l'Est, 31, 2: 249

Sloop, voir Voilier

SMELSER, Neil (sociologue), industrialisation et famille, 39, 2: 204

Société amicale et bienveillante des charpentiers de vaisseaux de Québec, 37, 2: 233236

Société canadienne d'éducation des adultes, participation à la préparation «Les Idées en marche» (émission d'affaires publiques), 36 , 2: 219,220

Société d'affaires, définition au $18 \mathrm{e}$ siècle, 40 , 3: 412,415

Société d'économie sociale, France, $36,1: 56$, 60

Société d'Hygiène de la province de Québec, promotion de l'hygiène publique, 35, 3: 364

Société de colonisation des Cantons de l'Est, $32,1: 21$ ss

Société de médecine de Québec, fondation, $34,2: 233$ 
Société de rapatriement et de colonlation du Lac Saint-Jean, 38, 3: 380-408

Société générale de colonisation et de rapatriement, émigration des Canadiens français, $33,2: 172$ ss

Société inter-universitaire de recherches sur les populations, 39, 1: 3; voir aussi Centre interuniversitaire de recherches sur les populations; Projet d'histoire sociale de la population du Saguenay

Société littéraire et historique de Québec, 35, 2: $179-192$

Société médicale de Montréal, 35, 3: 358 ss

Société par actions, développement, 38,2 : 182,183

Société pour l'encouragement des sciences et des arts au Canada, Québec (ville), 35, 2: $181 \mathrm{ss}$

Société Radio-Canada, émissions d'affaires publiques à la télévision, 36, 2: 213-239

Société régionale, pouvoir des élites, Saguenay-Lac Saint-Jean, 39, 1: 22, 23

Société rurale, aménagement en régions défavorisées, France-Québec, 35, 2: 253-261; hiérarchie de la paysannerie, seigneurie de Saint-Hyacinthe, 40, 3: 373-407; mariages exogames, Nouvelle-France, 35, 1: 3-32; solidarités communautairès, $40,1: 53-71$

Société Saint-Jean-Baptiste de Montréal, réforme de l'éducation, 36, 3: 346, 347

Sociétés de commerce des fourrures, Nouvelle-France, 40, 3: 409-428

Sociétés savantes, histoire des, indications bibliographiques, 35, 2: $200 \mathrm{ss}$; voir aussi Literary and Historical Society of Quebec

Socio-économie, histoire du Québec, 35, 4: 483-521

Socio-économie d'information, Québec (province), 35, 4: 517-519

Socio-économie-comptoir, Nouvelle-France, 35, 4: 493-496

Soeurs Grises, Crèche d'Youville, Montréal, 40, 4: 537-559; salles d'asile, Montréal, 34, 1: $27-55$

Soldats, vie des, Québec (ville), NouvelleFrance, 32, 4: 535-563

Soleil, Le (navire français), cargaison pour la Nouvelle-France, 36, 3: 417 ss

Solidarités communautaires, famille et société rurale, 40, 1: 53-71

Sorcellerie, seigneurie de Beaubassin, Acadie, Nouvelle-France, 37, 3: 405
Sorel (paroisse), agriculture, 39, 3: 407-413

SOUPRAS, Eustache (marchand), Bas-Richelieu (région), 38, 1: $11 \mathrm{ss}$

Sous-développement, théorie, 31, 1: 19-22

Specculation foncière, investissemnents de Timothy Hibbard Dunn, 35, 3: 327-329; tenure en franc et commun soccage, BasCanada, 36, 2: 182-190

St. Francis Courier and Sherbrooke Gazette (journal), 31, 2: 243-247

St. Lawrence and Atlantic (chemin de fer), construction, Sherbrooke, 31, 4: 525-545

St.Maurice Valley Cotton, Mauricie, 40, 1: 40

Statistiques du ministère du Travail, critique des sources, 37, 2: 222-225

Stocks de marchandises, voir Inventaire en magasins

STONE, Lawrence (historien), famille moderne, 39, 2: 206, 207

Structure socio-professionnelle, L'Assomption (village), 39, 3: 325, 326; migrants internes de Montréal, 35, 4: 528-531; voir aussi Professions

Suffrage féminin, discours des médecins-députés, 38, 1: 31; Québec (province): 32, 1: 318

Sulpiciens, Nouvelle-France, 31, 1: 51

Supérieur, lac, voyage de Jean Nicollet, Nouvelle-France, 34, 2: 183-196

Symposium de l'Université Laval (1952), répercussions sociales de l'industrialisation dans la province de Québec, 33, 3: 362-368

Syndicalisation, construction navale, Québec (ville), 37, 2: 233-236; taux, Québec (province) et Ontario, 37, 2: 205-211

Syndicalisme au Canada, historiographie canadienne-anglaise, 37, 2: 165-184

Syndicalisme catholique, 31, 2: 211-227; École sociale populaire, 32, 2: 203-228; imprimerie, 37, 2: 241-269; industrie de la chaussure, 36, 1: 92-96;

Syndicalisme catholique féminin, Hull, 32, 4: 603-628

Syndicalisme international, imprimerie, 37,2 : 241 ss; Québec (province) et Ontario, 37, 2: $205 \mathrm{ss}$; Union internationale des travailleurs en chaussures, Québec (province), 36, 1: 75-105

Syndicalisme québécois, historiographie, 37 , 2: 201-204; et nationalisme, 35, 3: 397-406

Syndicat catholique des imprimeurs-relieurs du diocèse d'Ottawa, 37, 2: 248 ss 
Syndicat catholique des allumettières de Hull, conflit avec la Compagnie E.B. Eddy, 32, 4: 614 ss

Syndicat catholique et national des imprimeurs de Chicoutimi, 37, 2: 255, 256, 262

Syndicat catholique et national des typographes de Montréal, 37, 2: 242, 248, 249

Syphilis, et mortalité infantile, Montréal, 36, 4: 513,514

Système agro-forestier, historiographie, 33, 1: 67-78; Saguenay-Lac Saint-Jean, 31, 1: 1217

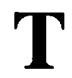

TACHÉ, Alexandre (archevêque de SaintBoniface), écoles du Manitoba, 33, 1: 7-9; émigration dans l'Ouest canadien, 33, 2 : 164 ss

Tadoussac, commerce des fourrures, NouvelleFrance, 31, 2: 173

Tadoussac, Ferme de, Nouvelle-France, 31, 2: 172 ss

Tamorôas (tribu amérindienne), mission de Dominique-Marie Varlet, Louisiane, 36, 2: 198-204

TANGUAY, Cyprien (généalogiste), dictionnaire généalogique, 33, 3: 430; naissances illégitimes, Nouvelle-France, 40, 2: 239, 240

Tannerie, Québec (ville), Nouvelle-France, 34, 3: 342 ss

TARDIVEL, Jules-Paul (journaliste), nationalisme, 32, 3: 363, 367, 368; émigration dans l'Ouest canadien, 33, 2: 169 ss

TASCHEREAU, Elzéar-Alexandre (archevêque de Québec), division du clergé, 33, 4: 503 ss

TASCHEREAU, Louis-Alexandre (premier ministre du Québec), opposition des JeuneCanada, 40, 1: 12-17

Technique de guerre, fort de Chambly, Nouvelle-France, 37, 1: 21-49

Techniques de production, agriculture, seigneurie de Saint-Hyacinthe, 40, 3: 383-387

Techniques et sciences au Canada, histoire des, historiographie, 35, 2: 193-215

Technologie, industrie minière, $37,4: 574-581$
Télévision, émissions d'affaires publiques à Radio-Canada, 36, 2: 213-239

TEMPLÉ, Edmond (professeur), direction générale des écoles du soir de Montréal, 34, 4: 605 ss

Tenure en franc et commun soccage, attitudes de la bourgeoisie marchande, Bas-Canada, 36, 2: 166 ss

Tenure seigneuriale, attitudes de la bourgeoisie marchande, Bas-Canada, 36, 2: 166 ss

Terre-Neuve, commerce de la morue en France, 36, 3:323-338; pêcheries, 39, 4: 523-549

Terre-Neuve/France, commerce de la morue, 36, 3: 323-338

Terre-Neuve/Marseille, commerce de la morue, 40, 2: 193-214

Terres, mode de transmission, Calixa-Lavallée (village), 34, 3: 331-339

Territorialité et culture, Nouvelle-France, 37, 3: $417-429$

Testament, étude de l'alphabétisation, 39, 1: 55,56 ; transmission des terres, CalixaLavallée (village), 34, 3: 336 ss

Testaments, clauses à caractère religieux, gouvernement de Québec, Nouvelle-France, $32,1: 57-94$

Textile, grève à la Ayers, Lachute, 37, 2: 271289 ; grève à la Bruck Silk Mill, Cowansville, 34, 2: 171-182; grève à la Dominion Textile, 31, 2: 217; Wabasso Cotton, Mauricie, $40,1: 35$ ss

Théâtre, Québec (province), 38, 4: 541; récits de voyage sur Paris, 38, 4: 558-560

THOMPSON, Edward P. (historien), influence au Canada anglais, 37, 2: 173 ss

Thouron Frères, chargés d'affaires de JeanBaptiste-Nicolas Roch de Ramesay à La Rochelle, France, 37, 4: 607, 608

Tiers ordre franciscain (confrérie), gouvernement de Québec, Nouvelle-France, 39, 4: 492 ss

Titre nouvel, droit de, renforcement par les seigneurs, 36, 2: 177

Titres cléricaux, origine sociale du clergé, 37 , 3: $382-388$

TOBIN, John F. (président de l'Union internationale des travailleurs en chaussures), $36,1,78$ ss

TOLFORD, Calvin (rédacteur du St. Francis Courier), 31, 2: 244-246

Tour Eiffel, récits de voyage sur Paris, 38, 4: 556 
Tourisme, Gaspésie, 36, 4: 501-505

TOUSIGNANT, Pierre (historien), attitudes des marchands britanniques envers le régime seigneurial, 35, 1:77

Township Reformer (journal), Stanbridge, 31, 2: 249

TRACEY, Daniel (médecin), élection partielle de 1832, Montréal, 32, 4: 566 ss

Trafic des bâtiments de commerce, France/ Nouvelle-France, 36, 3: 421-424

Trafic maritime, Terre-Neuve/France, 39, 4: 528-532

Traité de Paris, cession de l'Illinois français, $39,4: 589$

Traite des fourrures, voir Commerce des fourrures

Transactions, publication de la Literary and Historical Society of Quebec, 35, 2: 179 ss

Transition du féodalisme au capitalisme, 35, 1: 69-95; 39, 3: 369-389

Transport maritime, investissements de Timothy Hibbard Dunn, 35, 3: 329, 330

Transports, commerce de détail canadien, 33, 4: 525-527; voir aussi Voiturage

Trappistes, établissement d'un monastère dans le township de Ditton, Cantons de l'Est, 32, 1: 25,26

Travail à domicile, industrie de la chaussure, Montréal, 31, 2: 191 ss

Travail des enfants et instruction obligatoire, Québec (province), 38, 1: 39-58

Travail, division du, construction navale, Québec (ville), 37, 2: 229, 230; industrie de la chaussure, Montréal, 31, 2: 191 ss; Montréal, 33, 1: 44 ss

Travail domestique, filles, Québec (province), $38,1: 53$

Travail, législation du, 31, 2: 215-221

Travail, marché du, ethnicité, Canada, 38, 2 : 247.250

Travail, ministère du, critique des sources statistiques, 37, 2: 222-225

Travail, organisation du, Montréal, 33, 1: 3950

Travailleurs, Alcan, Saguenay, 37, 2: 291-308; construction de chemins de fer, Sherbrooke, 31, 4: 525-545; écoles du soir, 34, 4: 597 625; formation, Montréal, 33, 1: 39-50; mariages et famille, Sainte-Brigide (paroisse), 39, 2: 233-251; militantisme syndical, Québec (province) et Ontario, 37, 2: 204-222; rapports de production préindustrielle, 38, 2: 245-247; rôle de la famille dans leur formation, États-Unis, 39, 2: $192-$ 194

Tremblement de terre, Nouvelle-France, récit de François-Xavier de Charlevoix, 36, 3: 375-387

Trésorier général de la Marine en France, rôle et fonctions pour la Nouvelle-France, 32, 2: 184-186

Tribunaux, Bas-Canada, 38, 4: 508 ss

Troc, blé, monnaie d'échange, 36, 2: 242

Trois-Rivières (district), origine du clergé, 37 , 3: $377-380$

Trois-Rivières (région), Acadie, NouvelleFrance, 37, 3: 400 ss

Trois-Rivières (ville), Union internationale des travailleurs en chaussures, 36, 1: 90, 91

Trois-Rivières, gouvernement de, conceptions prénuptiales, Nouvelle-France, 40, 2: 264, 265

Troupes de la Marine, mode de paiement, Nouvelle-France, 32, 2: 191 ss

TRUDEAU, Pierre-Elliott (avocat), critique de l'oeuvre de Joseph-Papin Archambault, 35, 4: 584-586; mutations de la Confédération des travailleurs catholiques du Canada, 34, $3: 378,379$; ouvrage sur la grève de l'amiante, 37, 2: 203

Trusts, opposition des Jeune-Canada, 40, 1: 12

Tuberculose, mortalité, Québec (province), 36, 4: 514-516

TUKE, Samuel (médecin), traitement de la folie, 39, 3: 347, 348

TURCOTTE, Joseph-Édouard (avocat), activités patriotes, $38,1: 59-71$

Tycoon (industriel-financier), direction des entreprises, 38, 2: 183

Typhoïde, mortalité, Montréal, 36, 4: 518

$\mathbf{U}$

Ultramontanisme, conflit dans l'Église de France, 36, 2: 195 ss; messianisme, 34, 4: 558 ss; Programme catholique, 33, 4: 503, 504

Union des électeurs, voir Crédit social

Union des travailleurs industriels de la chaussure, syndicat catholique, 36, 1: 92 
Union internationale des travailleurs en chaussures, Québec (province), 36, 1: 75105

Union internationale des Ligues catholiques féminines, suffrage féminin au Québec, 32, 1: 6 ss

Union nationale, René Chaloult, 39, 1: 27 ss

Union protectrice des cordonniers-monteurs du Canada, 36, 1: 78-81

Union typographique internationale, 37,2 : 241 ss

Université de Montréal, organisation, 36, 1: 329; voir aussi École des Hautes études commerciales; École des sciences sociales, économiques et politiques

Université Laval, école de médecine, 37, 1: 58

Université Laval à Montréal, division du clergé, 33, 4: 508 ss

Université McGill, école de médecine, 37, 1: $58,59,61$

Urbanisation, histoire de la famille, 39, 2: $186 \mathrm{ss}$; histoire de la famille, Europe, 39, 2: 171-173, 182; hygiène publique, Montréal, 36, 4: 523-526; Montréal, 40, 4: 538 ss; naissance de l'asile, 39, 3: 348 ss; quartier Saint-Roch, Québec, 34, 4: 569-596; Québec (province), 36, 3:340, 341; réforme, Montréal, 37, 2: 185-199; Saguenay, 37, 2: 292; Saguenay-Lac Saint-Jean, 31, 1: 11 , 12 ; solidarités communautaires, $40,1: 65$ 69

Urbanité et culture, organisation du territoire, Nouvelle-France, 37, 3: 418 ss

Ursulines, confrérie du Sacré-Coeur, NouvelleFrance, 39, 4: 498, 512, 513

Utrecht, Église d', dissidence avec l'Église de Rome, 36, 2: 209-212

Vaccination, Conseil d'Hygiène de la province de Québec, 35, 3: 366; introduction au Québec, 34, 2: 240; variole, Montréal, 36, 4: 516,517

VAILLANCOURT, Cyrille (sénateur), Ordre de Jacques-Cartier, 40, 2: 284

Vaisselle des artisans, Québec (ville) et Montréal, Nouvelle-France, 40, 3: 359-365
VALLIÈRES DE SAINT-RÉAL, Joseph-Rémi (homme politique), loi sur l'endettement, 40, 2: 229,230

VALLIĖRES, Pierre (membre du Front de Libération du Québec), procès, 34, 1: 86, 87

VAN, Ta (politicologue), effets de la Conquête, 39, 3: 369 ss

VANFELSON, George (homme politique), droit de la faillite, Bas-Canada, 40, 2: 232, 233

Varennes (paroisse), François-Augustin Bailly de Messein, 33, 2: 215-262

Variole, vaccination, Montréal, 36, 4: 516, 517

VARLET, Dominique-Marie (prêtre), réforme de l'Église catholique, 36, 2: 195-212

VATTEMARE, Alexandre (scientifique), Institut Vattemare, 31, 1: 75-78

VAUBAN, Sébastien Le Prestre de (ingénieur), architecture des fortifications, 37,1 : $30 \mathrm{ss}$

Vaudreuil, École de formation sociale, oeuvre de l'École sociale populaire, 35, 4: 575à 577

VAUDREUIL, Philippe de Rigaud de (gouverneur de la Nouvelle-France), défense de la Nouvelle-France, 37, 1: 23 ss

VAUDREUIL, Pierre de Rigaud de (gouverneur général du Canada), oeuvre de Guy Frégault, 35, 1: 62-63

Ventes à l'encan, marchands-négociants, Québec (ville), 36, 4: 536, 537

Ventes sur les quais, marchands-négociants, Québec (ville), 36, 4: 537

Verchères (paroisse), François-Augustin Bailly de Messein, 33, 2: 224 ss

Verchères (seigneurie), transmission des terres, 34, 3: 331-339

Veuvage, influence sur l'exogamie, NouvelleFrance, 35, 1: 17 ss

Veuvage et remariage, Nouvelle-France, Nouvelle-Orléans, Saint-Domingue, 39, 2: 221224,228

Veuves, conceptions prénuptiales, NouvelleFrance, 40, 2: 261-263; naissances illégitimes, Nouvelle-France, 40, 2: 247, 248

VICERO, Ralph (géographe), émigration des Canadiens français, 38, 3: 411, 412

Vie matérielle, artisans, Québec (ville) et Montréal, Nouvelle-France, 40, 3: 355-372

Vie militaire, Nouvelle-France, $32,4: 535-563$

Vie syndicale (journal), 31, 2: 218; condamnation de l'appui du Congrès des métiers et du 
travail du Canada au Front populaire espagnol, 33, 4: 579-580

VIGER, Denis-Benjamin (homme politique), droit de la faillite, Bas-Canada, 40, 2: 226228

VIGER, Jacques (maire de Montréal), particularismes de la langue française au Canada, 35, 3: 338

VIGER, Joseph (marchand), L'Assomption (village), 39, 3: 331, 334

Ville, âge au baptême, Nouvelle-France, 38, 3: 347, 353, 354; conceptions prénuptiales, Nouvelle-France, 40, 2: 265-267; criminalité, Bas-Canada, 38, 4: 512, 513; démographie différentielle, Nouvelle-France, 38,3 : 357-378; naissances illégitimes, NouvelleFrance, 40, 2: 242-244; recrutement du clergé, $37,3: 380 \mathrm{ss}$

Villes, lien entre langue française et religion catholique, Canada, 33, 2: 263-265

Villes, contrôle sanitaire, Conseil d'Hygiène de la province de Québec, 35, 3: 370, 371

Violence, histoire du Québec, 37, 1: 67-79

VITRÉ, Charles Denis de (entrepreneur), pêche au marsouin, Nouvelle-France, 37, 4: 544,545

Voilier, construction navale, vallée du SaintLaurent, 35, 2: $239 \mathrm{ss;}$ navigation sur le Richelieu, 38, 1: 16-20

Voisinage, liens de, travailleurs, Sainte-Brigide (paroisse), 39, 2: 246

Voiturage, industrie du, Montréal, 31, 3: 371395

Voyageurs, sociétés de commerce des fourrures, Nouvelle-France, 40, 3: 421-428

\section{Articles par sujet}

W

Wabasso Cotton Ltd, Mauricie, 37, 1: $10 \mathrm{ss;}$ 40, 1: 35 ss

WADE, Mason (historien), influence au Québec, 33, 3: 371, 372; Jeune-Canada, 40, 1: 9

WALLOT, Jean-Pierre (historien), crise agricole, 38, 2: 231-233; hiérarchie de la paysannerie, 40, 3: 377, 378; histoire du BasCanada, 34, 3: $416 \mathrm{ss;}$; inventaires après décès, 34, 4: 515 ss; sens de l'histoire, 37, 4: $533-542$

WALTON, Joseph Soper (rédacteur du Farmer's Advocate and Townships Gazette), 31, 2: 247,248

WARIAN, Peter (historien), syndicalisme au Canada, 37, 2: 172, 173, 177

Wayagamack Pulp and Paper Limited, Mauricie, 40, 1: 42, 43

WIALLARD, Paul (directeur de l'agence d'immigration à Paris), 34, 3: 361 ss

Winnipeg, grève générale de, procès, 34,1 : 70-74

WUYTIERS, Barchman (évêque d'Utrecht), $36,2: 210,211$

7

ZOLTVANY, Yves (historien), Coutume de Paris, 34, 3: 334 